NASA Technical Memorandum 110331

U.S. Army Research Laboratory Technical Report 1342
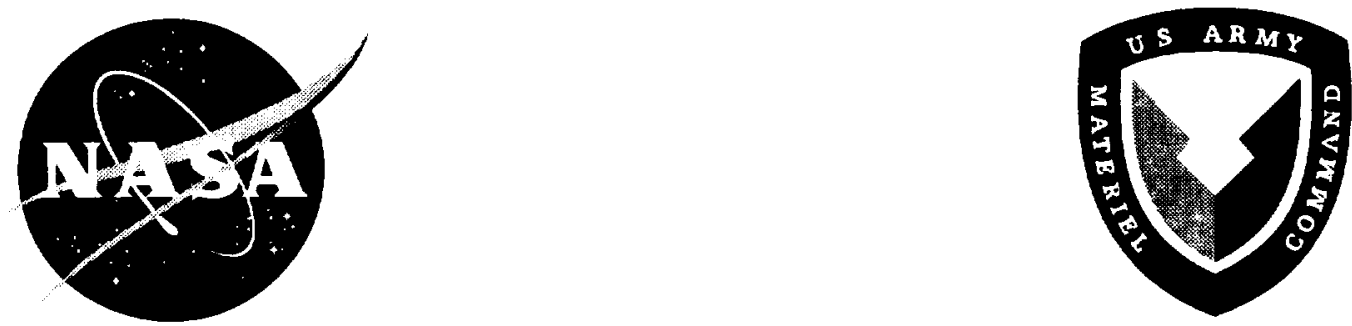

\title{
Fatigue Debonding Characterization in Composite Skin/Stringer Configurations
}

Michael K. Cvitkovich

National Research Council Resident Research Associate

Langley Research Center, Hampton, Virginia

T. Kevin $\mathrm{O}^{\prime}$ Brien

Vehicle Technology Center

U.S. Army Research Laboratory

Langley Research Center, Hampton, Virginia

Pierre J. Minguet

Boeing Defense $\mathcal{E}$ Space Group, Philadelphia, Pennsylvania

April 1997

National Aeronautics and

Space Administration

Langley Research Center

Hampton, Virginia 23681-0001 



\section{ERRATA}

NASA Technical Memorandum 110331

\section{Fatigue Debonding Characterization in Composite}

Skin/Stringer Configurations

Michael K. Cvitkovich, T. Kevin O'Brien, and Pierre J. Minguet

April 1997

Page 13, Table 2: Column 2 heading should read $\mathrm{E}_{22}, \mathrm{GPa}$.

A revised copy of the report is attached. Please destroy all copies previously sent to you. 



\title{
Fatigue Debonding Characterization in Composite Skin/Stringer Configurations
}

\author{
Michael K. Cvitkovich ${ }^{I}$, T. Kevin O'Brien ${ }^{2}$ and Pierre J. Minguet ${ }^{3}$
}

\begin{abstract}
The objective of this work was to investigate the fatigue damage mechanisms and to identify the influence of skin stacking sequence in carbon epoxy composite bonded skin/stringer constructions. A simple 4-point-bending test fixture originally designed for previously performed monotonic tests was used to evaluate the fatigue debonding mechanisms between the skin and the bonded frame when the dominant loading in the skin is flexure along the edge of the frame. The specimens consisted of a tapered flange, representing the stringer, bonded onto a skin. Based on the results of previous monotonic tests two different skin lay-ups in combination with one flange lay-up were investigated. The tests were performed at load levels corresponding to $40 \%, 50 \%$, $60 \%, 70 \%$ and $80 \%$ of the monotonic fracture loads. Microscopic investigations of the specimen edges were used to document the onset of matrix cracking and delamination, and subsequent fatigue delamination growth. Typical damage patterns for both specimen configurations were identified. The observations showed that failure initiated near the tip of the flange in the form of matrix cracks at one of two locations, one in the skin and one in the flange. The location of the $90^{\circ}$ flange and skin plies relative to the bondline was identified as the dominant lay-up feature that controlled the location and onset of matrix cracking and subsequent delamination. The fatigue delamination growth experiments yielded matrix cracking and delamination onset as a function of fatigue cycles as well as delamination length as a function of the number of cycles.
\end{abstract}

KEY WORDS: composite materials, fatigue testing, design, bond strength, skin/flange interface, secondary bonding

${ }^{1}$ National Research Council Resident Research Associate, NASA Langley Research Center, Mail Stop 188E, Hampton, VA 23681-0001

2 Senior Scientist, U.S. Army Research Laboratory, Vehicle Technology Center, NASA Langley Research Center, Mail Stop 188E, Hampton, VA 23681-0001

${ }^{3}$ Senior Tech Specialist, Boeing Defense \& Space Group, Helicopters Division, P.O. Box 16858, Mail Stop P38-13, Philadelphia, PA 19142-0858 


\section{Introduction}

One of the major objectives of today's aircraft industry is the reduction of manufacturing costs without loss, or with even an increase, in quality and reliability. One of the many approaches to achieve this goal is the simplification of the production processes. Composite structures have already proven to be very cost-effective due to their lightweight design. These structures are also very attractive since secondary bonding or co-curing may replace mechanical fastening methods, and reduce component assembly time.

As of today, little data exist on the mechanical capabilities of bonded skin/stringer structures. First investigations have been performed on the effects of pressure loading on a state-of-the-art composite materials bonded fuselage panel [1]. Due to flexure along the edge of the frame (see Fig. 1), shear stresses and moments along the frame length were identified as potentially critical loading conditions very likely to result in structural failure. Experiments under monotonic loading conditions were carried out utilizing a modified frame pull-off test with specimens cut from a full-size panel. The major drawback of this test methodology is the expensive production of the pull-off specimens and the complex test setup.

Based on these results, a new test methodology for analyzing the failure mechanisms at the skin/stringer interface has recently been introduced [2,3]. Comparatively simple specimens consisting of a flange bonded onto a skin were tested in three- and four-point bending fixtures. It was shown in experiments with monotonic loading that failure initiated at the tip of the flange, identical to the failure mode in complex specimens tested in Reference 1. Depending on specimen lay-up, delaminations were reported to propagate at two different locations, either in the flange or in the skin [3]. A later examination of the specimens tested under monotonic loading revealed that in one specimen configuration debonding also occurred between the flange and the skin within the bondline.

To obtain a more complete understanding of skin/stringer debonding mechanisms, it is vital to perform fatigue tests along with the monotonic experiments to establish the durability of these bonded joints over the anticipated life cycle. Unfortunately, no such data are available in the 
literature. Therefore, the objective of this investigation was to shed more light onto fatigue skin/stringer debond failure. Four-point bending fatigue tests were carried out using the same specimen configurations and fixtures used in References 2 and 3. Two specimen configurations with the same flange lay-up but with different skin lay-ups were investigated to evaluate the influence of the ply stacking sequence on the fracture mode near the bondline.

\section{Materials and Specimen Preparation}

The specimens for fatigue loading were identical to the specimens used in previous monotonic tests $[2,3]$ They were machined from the same panels and consisted of a bonded skin and flange assembly shown in Fig. 2. To study the influence of skin lay-up only, two skin laminates, labeled S1 and S3, and one flange laminate, labeled F1, were combined to give two specimen configurations, A and D (see Table 1). The terms S1, S3, F1, A and D were chosen in accordance with the nomenclature used for monotonic testing [3]. Two panels of each configuration were produced. Both the skin and the flange laminates had a multidirectional lay-up, containing $0^{\circ}, 90^{\circ},+45^{\circ}$ and $-45^{\circ}$ plies. Moreover, the skin lay-ups were chosen to give an almost identical bending stiffness, $D_{11}$. Laminate characteristics and $0^{\circ}$ ply material properties are summarized in Tables 1 and 2, respectively.

Both the skin and flange were made from IM6/3501-6 graphite/epoxy prepreg tape with a nominal ply thickness of $0.188 \mathrm{~mm}$. First, the flange and skin laminates were cured separately. The flange parts were then cut into $50 \mathrm{~mm}$ long strips and machined with a $27^{\circ}$ taper along the edges. Subsequently, the flange was adhesively bonded to the skin using a $177^{\circ} \mathrm{C}$ cure film adhesive from America Cyanamid (CYTEC 1515). A grade 5 film was used to yield a nominally $0.127 \mathrm{~mm}$ thick bondline. However, because some of the adhesive flowed outwards during cure, the actual bondline thickness was $0.102 \mathrm{~mm}$. Moreover, one panel of configuration D showed ply waviness and ply drops on one flange side due to fabrication imperfections as shown in Fig. 3. A diamond saw was used to cut the panels into $25 \mathrm{~mm}$ wide by $127 \mathrm{~mm}$ long specimens. The specimen dimensions are shown in Fig. 2a). 


\section{Experimental Procedure}

The same four-point bending test configuration used for monotonic testing was employed to perform the fatigue tests $[2,3]$. A schematic of the test fixture is shown in Fig. 2b). The bottom support had a $102 \mathrm{~mm}$ span, while the upper fixture had a $76 \mathrm{~mm}$ span. Mid-span deflection was recorded using a spring loaded direct current displacement transducer (DCDT) contacting the center of the frame flange as shown in Fig. 2b). The experiments were performed in a servohydraulic load frame in load control at a cyclic frequency of $5 \mathrm{~Hz}$ and an R-ratio of 0.1 . From the monotonic tests a load, $P_{n l}$, was determined at which the load versus stroke curves deviated slightly from the initial linear slope [3]. The average value of $P_{n l}$ for the monotonic tests was found to be $1470 \mathrm{~N}$ for configuration $\mathrm{A}$ and $1220 \mathrm{~N}$ for configuration $\mathrm{D}$. It was assumed that at this load level possible damage initiation may occur. When comparing different test configurations or when dealing with structural components, calculating the bending moment in the skin at the tip of the flange has been shown to be a better way of analyzing the data [1]. Since only one test configuration was used in the present investigation the data are still displayed in terms of load. However, for reasons of comparison the bending moment at the tip of the flange may easily be calculated as $\left(P_{n l} / 2\right)$ times the moment arm of $12.7 \mathrm{~mm}$.

For each configuration, fatigue tests were run at load levels corresponding to $40 \%, 50 \%$, $60 \%, 70 \%$ and $80 \%$ of the load. Two tests were performed at the five levels with the exception of $40 \%$, where only one specimen was tested. The cyclic loading was stopped at fixed intervals depending on the load level, and a photograph of the polished specimen edge was taken under a light microscope to document the occurrence and growth of matrix cracks and delaminations. Table 3 lists the schedule used to obtain photographs for each cyclic load level. Damage was documented based on location at each of the four corners identified in Fig. 4. The specimens were clamped into a three-point bending rig as shown in Fig. 5 and a small load was applied by hand tightening a set screw while the specimen and rig were placed under the microscope to open the matrix cracks and delaminations slightly, thereby increasing the visibility of the damage. Furthermore, at each interval the specimens were loaded monotonically to the mean load, and a plot of load versus mid- 
span deflection was recorded using an X-Y plotter. As damage was initiated the specimen compliance, given by the slope of the plot, increased. Tests run at $40 \%, 50 \%$ and $60 \%$ were terminated at 1000000 (one million) cycles. Unless specified otherwise in the text, tests at $70 \%$ and $80 \%$ were terminated at 100000 cycles. To investigate the influence of the fabrication imperfections in one panel of configuration $\mathrm{D}$, two additional specimens were cut from that panel and were tested at load levels of $70 \%$ and $80 \%$ of $P_{n l}$.

\section{Results and Discussion}

\section{Specimen Configuration A}

In Fig. 6, results of configuration A are summarized for the two replicate specimens at each load level as a plot of the number of cycles to the onset of matrix cracking and subsequent delamination. In some cases, a left hand arrow indicates damage initiation within the first 100 cycles. At a load level of $40 \%$, a right hand arrow shows that no delaminations occurred within the test period of 1000000 cycles. The loads at onset of damage obtained from the monotonic tests are shown at the ordinate. These data points represent a load level of $100 \%$ of $P_{n l}$. A clear distinction between matrix cracking and delamination onset can be observed from the plot. Furthermore, a linear relationship between $P_{\max }$ and $\log N$ exists for each event, with very little scatter between the two replicates tested at each load level. The number of cycles between onset of matrix cracking and delamination covers a little over one order of magnitude for all load levels investigated. A linear extrapolation of the fatigue data for matrix cracking onset and delamination onset suggests that no time delay exists between matrix cracking and delamination formation during monotonic loading. This is also consistent with the results at the highest fatigue load level $(80 \%)$ where both events occurred within the same observation period.

Typical damage patterns observed in specimens of configuration A are shown in Fig. 7. These drawings are based on the microscopic investigation performed during the tests. As shown in Fig. 7a), initial matrix cracks formed first at corners 2 and 3, typically in the $90^{\circ}$ flange ply as 
described in Reference 3. They initiated further matrix cracks in the lower $45^{\circ}$ flange ply. Subsequently, delaminations (labeled "B" for bondline failures) formed from these matrix cracks. These "B" delaminations ran to one side of the interface between the bondline and the composite, usually the top skin ply interface. The first delamination always corresponded to the first matrix crack that formed. They were followed by delaminations between plies (labeled "P") at corners 1 and 4. In some specimens, the "P" delaminations initiated in the $-45^{\circ} / 90^{\circ}$ flange ply interface with no matrix crack, whereas, in other specimens they initiated from matrix cracks in the $90^{\circ}$ flange ply. Both scenarios are displayed in Fig. 7b). "P" delaminations always resulted in a delamination running in the $90^{\circ} / 45^{\circ}$ flange ply interface. Each flange side (side $1=$ corners 1 and 2 , side $2=$ corners 3 and 4) consisted of a "P" and a "B" delamination. At each flange side, the "P" delaminations started later than the corresponding "B" delaminations, but almost immediately equaled or exceeded them in length. As the "P" delaminations grew, they would tend to arrest and form new matrix cracks branching into the bottom $45^{\circ}$ flange ply (see Fig. 7b)). These matrix cracks always stopped at the bondline. After the matrix crack had formed the delamination would start to grow again. Delaminations arrested only beyond the tapered region of the flange. No branching into the skin ply or into the bondline was observed. As an example, Figures 8 and 9 show micrographs of a configuration A specimen tested at $80 \%$ of $P_{n l}$ exhibiting typical "B" and "P" damage patterns.

In Figures 10 to 17, the results are shown as plots of delamination length (see Fig. 7 for definition) versus the number of cycles for each load level for the configuration A specimens with delaminations. At a maximum load, $P_{\max }$, of $80 \%$ of $P_{n l}$ (see Fig. 10 and Fig. 11), matrix cracks and delaminations had formed within the first 100 cycles in both specimens. The tests were terminated at crack lengths of about $20 \mathrm{~mm}$, corresponding to almost total debonding of the flange from the skin. At $P_{\max }$ of $70 \%$ of $P_{n l}$ (see Fig. 12 and Fig. 13), matrix cracks also formed within the first 100 cycles in both specimens. As delaminations grew from all four corners, delaminations on side 1 tended to slow down while delaminations on side 2 continued to grow until the tests were terminated. At $P_{\max }$ of $60 \%$ of $P_{n l}$ (see Fig. 14 and Fig. 15), matrix cracks formed in all 
specimens within the first 1000 cycles. Delaminations on side 2 grew faster than delaminations on side 1. At $P_{\max }$ of $50 \%$ of $P_{n l}$ (see Fig. 16 and Fig. 17), matrix cracks formed first between 4000 and 6000 cycles in the $90^{\circ}$ flange ply closest to the skin, initiating a single delamination in the bondline of each specimen after 100000 cycles. In one specimen, the delamination formed at corner 3 while in the second specimen it formed at corner 2 . At $P_{\max }$ of $40 \%$ of $P_{n l}$, only one specimen was tested. A single transverse matrix crack formed at 45000 cycles at corner 3 in the $90^{\circ}$ flange ply closest to the skin. No delaminations formed within one million cycles.

\section{Specimen Configuration D}

In Fig. 18, results of configuration D are summarized as a plot of the number of cycles to the onset of matrix cracking and subsequent delamination. At a load level of $80 \%$, a left hand arrow indicates matrix cracking within the first 100 cycles. At other load levels, a right hand arrow shows that no delaminations or matrix cracks occurred within the test period of either 100000 or 1000000 cycles. The loads at onset of damage obtained from the monotonic tests are shown at the ordinate. These data points represent a load level of $100 \%$ of $P_{n l}$. In contrast to configuration A, no clear differentiation between matrix cracking and delamination onset is seen as the scatter for each event is significantly higher. Hence, the data overlap and no delay between those two events is apparent. The data scatter and the random manner of delamination growth also reflects the higher scatter compared to configuration A observed in monotonic tests. At the investigated load levels, the presence of an imperfection in the form of a flange ply drop does not seem to have any influence on either event. This is shown in Fig. 19, where the data from Fig. 18 are replotted for onset to matrix cracking only to discriminate between ideal specimens and specimens with flange ply drop. In one of the two specimens tested at $50 \%$ and at $40 \%$, both matrix cracking and delamination formation could not be observed within the test duration.

Unlike the previous specimen configuration A that was tested, delaminations in specimens of configuration D propagated in a more random manner. The only consistency found in the damage patterns is related to the four flange corners (see drawings in Fig. 20). 
Transverse matrix cracks typically formed in the $90^{\circ}$ skin ply closest to the flange at corner 1 in all specimens and at corner 4 in specimens with no flange ply drop ("ideal") (see top section of Fig. 20a)). Subsequently, these $90^{\circ}$ skin ply cracks initiated matrix cracks in the $45^{\circ}$ ply below, which in turn initiated delaminations in the $45^{\circ} 0^{\circ}$ interface. Once the delamination started to grow, the adhesive pocket also cracked. However, in the specimens with internal ply drops on one flange side (see Fig. 3 and bottom section of Fig. 20a)), matrix cracks at corner 4 formed first in the ply drop region of the bottom $45^{\circ}$ or $90^{\circ}$ flange ply and in the bondline and then initiated further matrix cracks and delaminations as described above. The majority of these delaminations stayed in the $45^{\circ} / 0^{\circ}$ interface. In some specimens, however, those delaminations started to split into the two $0^{\circ}$ plies at longer crack lengths. These events are labeled "split" in Fig. 20.

At corners 2 and 3, no consistent correlation between the flange imperfections and the damage patterns was observed. Typically, some transverse matrix cracks formed in the $90^{\circ}$ skin ply closest to the flange, initiating a delamination in the $90 \% 45^{\circ}$ interface as depicted in the top section of Fig. 20b). The other matrix cracks formed either in the flange ply drop region (not shown) or in the $90^{\circ}$ flange ply closest to the skin, initiating further matrix cracks in the bottom $45^{\circ}$ flange ply shown in the bottom section of Fig. 20b). Subsequently, a short delamination formed in the bondline, creating another matrix crack in the $90^{\circ}$ top skin ply. At the end of this transverse crack a delamination formed in the $90^{\circ} / 45^{\circ}$ interface. At this point, all delaminations started to grow in a similar manner. As they propagated, they would tend to arrest and form new matrix cracks branching into the top $45^{\circ}$ skin ply. These matrix cracks always stopped at the $45^{\circ} / 0^{\circ}$ interface After the matrix crack had formed the delamination would start to grow again. However, delamination arrest was not related to any position within the laminate. As the delaminations grew further, they started to branch into the lower $45^{\circ} / 0^{\circ}$ interface (labeled "branch" in Fig. 20), along with subsequent crack splitting into the two $0^{\circ}$ plies. Branching and splitting were either detected within the same observation cycle or occurred within a few thousand cycles of each other. As an example, micrographs of a specimen tested at $80 \%$ of $P_{n l}$ display typical damage patterns in 
Figures 21 and 22. In Figures 23 to 31, the results are shown as plots of delamination length versus the number of cycles for each load level for the specimens with delaminations.

At $P_{\max }$ of $80 \%$ of $P_{n l}$ (see Figures 23 to 26), matrix cracks formed first between 100 and 2000 cycles. Subsequently, delaminations formed from these matrix cracks. The first delamination always corresponded to the first matrix crack that formed. Only in one specimen (D16) were no branching and splitting found, which is most likely due to the comparatively very short crack lengths at test termination.

At $P_{\max }$ of $70 \%$ of $P_{n l}$ (see Figures 27 to 29), matrix cracks formed first between 1000 and 50000 cycles. In some cases, delaminations formed from these matrix cracks. For the "ideal" specimens without a flange ply drop, the first delamination always corresponded to the first matrix crack that formed. In one specimen with a flange ply drop, a matrix crack occurred at 1000 cycles but did not result in a delamination for the time span investigated. Instead, at 18000 cycles a matrix crack and a delamination formed at a different corner. In the second specimen with a flange ply drop, a single matrix crack occurred at 50000 cycles. No other matrix cracks and no delamination formed in this specimen before the test was terminated.

At $P_{\text {max }}$ of $60 \%$ of $P_{n l}$ (see Fig. 30), matrix cracks formed first between 20000 and 400000 cycles. In one of the two specimens tested at this load level, delaminations formed from these matrix cracks. The first transverse matrix crack formed at corner 4 . Subsequently, a matrix crack formed at corner 3 and initiated a delamination in the $90^{\circ} / 45^{\circ}$ interface at 140000 cycles. At 250000 cycles another matrix crack formed at corner 4 in the $45^{\circ}$ ply below the top $90^{\circ}$ skin ply. It instantly initiated a delamination in the $45^{\circ} / 0^{\circ}$ interface. In the other specimen, a matrix crack formed at 400000 cycles but did not result in a delamination.

At $P_{\text {max }}$ of $50 \%$ of $P_{n l}$ (see Fig. 31), a single matrix crack and a delamination formed only in one of the two specimens within the period investigated. In this specimen, the only matrix crack occurred at 130000 cycles at corner 3 in the $90^{\circ}$ skin ply closest to the flange. It resulted in a delamination in the $90^{\circ} / 45^{\circ}$ interface, forming at 200000 cycles. No matrix cracks and 
delaminations were detected in the second specimen. At $P_{\max }$ of $40 \%$ of $P_{n l}$, no matrix cracks and delaminations formed within one million cycles.

\section{Configuration comparison}

In Fig. 32, the two specimen configurations are compared with respect to the onset of matrix cracking. Matrix cracking typically occurred earlier in configuration A where $90^{\circ}$ plies in the flange were close to the bondline as in configuration D but $90^{\circ}$ plies in the skin were not. Again, left hand arrows indicate damage within the first 100 cycles, while right hand arrows show that no matrix cracks were observed within the test period of one million cycles. While specimens of configuration A show very little scatter, the data for configuration D displays significant variability at each load level. It is believed that this scatter is related to the transverse tension strength of the surface $90^{\circ}$ skin ply. This large variability has also been found in $90^{\circ}$ flexural fatigue tests performed in Reference 4.

Another way of comparing the results is to show the number of cycles to delamination onset once a matrix crack has already formed. This can be established by simply subtracting the number of cycles to onset of matrix cracking from the number of cycles to delamination onset. The combined data for configurations A and D are shown in Fig. 33. As pointed out before, in some cases both events occurred within the first 100 cycles or could not be detected until the tests were terminated. Hence, as no complete information of these damage stages was obtained these data points have been excluded from the graph. Right hand arrows indicate that matrix cracking occurred within one million cycles whereas delaminations did not occur. Although both configurations have been tested at different absolute load levels, there is little difference in the fatigue response for delamination onset between the two configurations once matrix cracks are

formed. As noted before, with decreasing load levels the number of cycles to delamination onset is shifted towards higher values. The scatter for the onset of delamination once a matrix crack has formed in specimens of configuration $D$ is smaller than observed for matrix cracking alone, indicating that delamination onset is not so sensitive to the skin lay-up. 


\section{Summary and Conclusions}

This paper addresses the fatigue debonding behavior of multidirectional composite skin/stringer configurations. Two different specimen configurations, A and D, were tested at various load levels in four-point bending to investigate the influence of skin stacking sequence. The specimens were examined at discrete time intervals under a light microscope to study the location of damage onset and subsequent damage progression. The location of the $90^{\circ}$ skin and flange plies relative to the bondline was identified as the dominant lay-up feature that controls the location and onset of matrix cracking and subsequent delamination.

In specimens of configuration $\mathrm{A}$, delaminations always initiated from a matrix crack in the flange, near the flange tip and then grew at slightly different rates depending on delamination location (between the flange or skin plies or at the bondline). All three failure modes have also been observed in monotonic experiments previously performed. For specimen configuration $\mathrm{D}$, matrix cracks formed either in $90^{\circ}$ plies in the skin, as reported for monotonic tests, or in the flange. In both events, damage initiation was again limited to an area near the tip of the flange. Subsequently, delaminations always grew in the skin, eventually exhibiting branching into lower interfaces and splitting within $0^{\circ}$ plies at longer crack lengths. Flange ply drops due to fabrication imperfections observed in some specimens did not result in different damage patterns.

As expected, damage onset and propagation was shifted towards higher lifetimes as load levels decreased. At $40 \%$ of the monotonic failure initiation load no damage progression could be observed in either configuration within the test period of one million cycles. Again, specimens cut from laminates with flange ply drops due to manufacturing imperfections did not exhibit different fatigue crack growth behavior. Matrix cracking typically occurred earlier in configuration A where $90^{\circ}$ plies in the flange were close to the bondline but $90^{\circ}$ plies in the skin were not. However, a comparison of both configurations shows that the number of cycles to delamination onset once matrix cracks are present does not strongly depend on skin lay-up. The comparatively high scatter in the fatigue data for specimen configuration $\mathrm{D}$ and the random manner of delamination growth observed for this configuration also reflect the scatter observed in monotonic tests. It is believed 
that this scatter is related to the low transverse tension strength of the surface $90^{\circ}$ skin ply as pointed out in Reference 3. This large variability has also been found in $90^{\circ}$ flexural fatigue tests. Finally, it can be concluded that when designing for bending stiffness, the skin and flange stacking sequences with the $90^{\circ}$ plies located as far away from the bondline as possible should be the most durable in terms of matrix cracking and delamination formation and growth.

\section{Acknowledgments}

This work was performed while the first author held a National Research Council Research Associateship supported by the US Army Research Laboratory Vehicle Technology Center at NASA Langley Research Center.

\section{References}

[1] Minguet, P. J., Fedro, M. J., O'Brien, T. K., Martin, R. H., Ilcewicz, L. B., Awerbuch, J., and Wang, A., "Development of a Structural Test Simulating Pressure Pillowing Effects in a Bonded Skin/Stringer/Frame Configuration," Proceedings, Fourth NASA/DoD Advanced Composites Technology Conference, Salt Lake City, UT, June 1993.

[2] Minguet, P. J. and O'Brien, T. K., "Analysis of Test Methods for Characterizing Skin/stringer Debonding Failures in Reinforced Composite Panels," Composite Materials: Testing and Design, Twelfth Volume, ASTM STP 1274, August 1996, p. 105-124.

[3] Minguet, P. J. and O'Brien, T. K., "Analysis of Composite Skin/stringer Failure Using a Strain Energy Release Rate Approach," Proceedings, Tenth International Conference on Composite Materials (ICCM X), Vancouver, British Columbia, Canada, August 1995, Vol. 1, pp. 245-252.

[4] Peck, A. W., "Transverse Tension Fatigue Characterization of Composite Materials," To be presented at the Seventh ASTM Symposium on Composite Materials: Fatigue and Fracture, ASTM STP 1330, St. Louis, MO, May 1997. 
Table 1--Laminate characteristics.

\begin{tabular}{cccc}
\hline & Lay-up & Skin/Flange Thickness, mm & Bending Stiffness $D_{11}, \mathrm{Nm}$ \\
\hline S1 & {$[45 /-45 / 0 / 0 / 45 / 90 /-45]_{\mathrm{s}}$} & 2.8 & 112 \\
S3 & {$[90 / 45 / 0 / 0 /-45 / 45 /-45 / \overline{90}]_{\mathrm{s}}$} & 3.0 & 117 \\
F1 & {$[45 / 90 /-45 / 0 / 90]_{\mathrm{s}}$} & 2.0 & 22.5 \\
\hline
\end{tabular}

Configuration $\mathrm{A}=\mathrm{S} 1+\mathrm{F} 1$

Configuration $\mathrm{D}=\mathrm{S} 3+\mathrm{F} 1$

Table 2-IM6/3501-6 unidirectional graphite/epoxy tape material properties.

\begin{tabular}{cccc}
\hline$E_{11}, \mathrm{GPa}$ & $E_{22}, \mathrm{GPa}$ & $G_{12}, \mathrm{GPa}$ & $v_{12}$ \\
\hline 144.8 & 9.7 & 5.2 & 0.3 \\
\hline
\end{tabular}

Table 3-Photographic schedule.

\begin{tabular}{ccc}
\hline & \multicolumn{2}{c}{ Between Cycles $N_{1}$ and $N_{2}$} \\
\cline { 2 - 3 } Photograph taken every $N$ cycle & $N_{1}$ & $N_{2}$ \\
\hline 100 & 1 & 100 \\
1000 & 100 & 10000 \\
2000 & 10000 & 20000 \\
5000 & 20000 & 50000 \\
10000 & 50000 & 100000 \\
20000 & 100000 & 300000 \\
50000 & 300000 & 700000 \\
100000 & 700000 & 1000000 \\
\hline
\end{tabular}




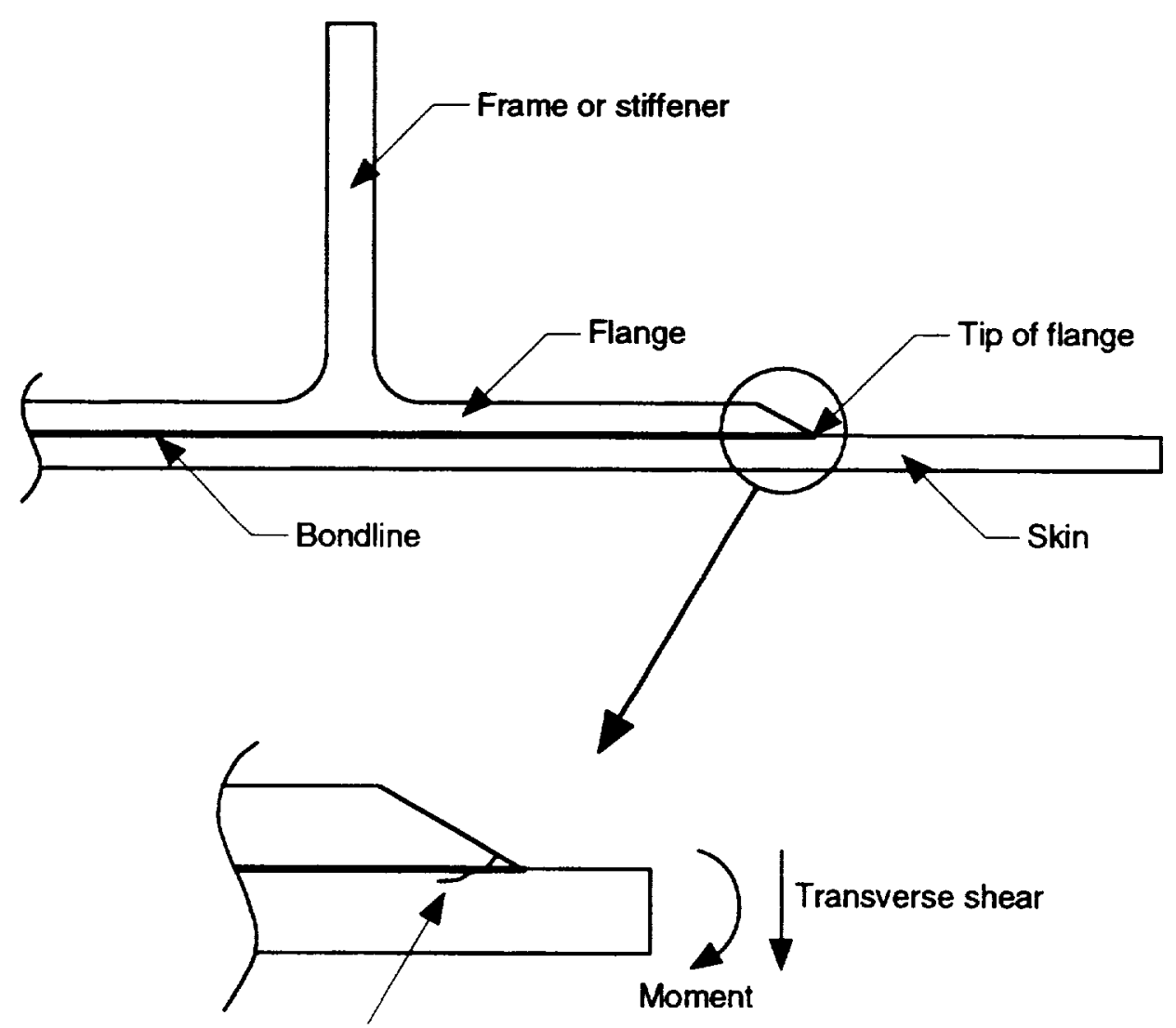

Failure initiation

Fig. 1-Illustration of frame/skin interface. 


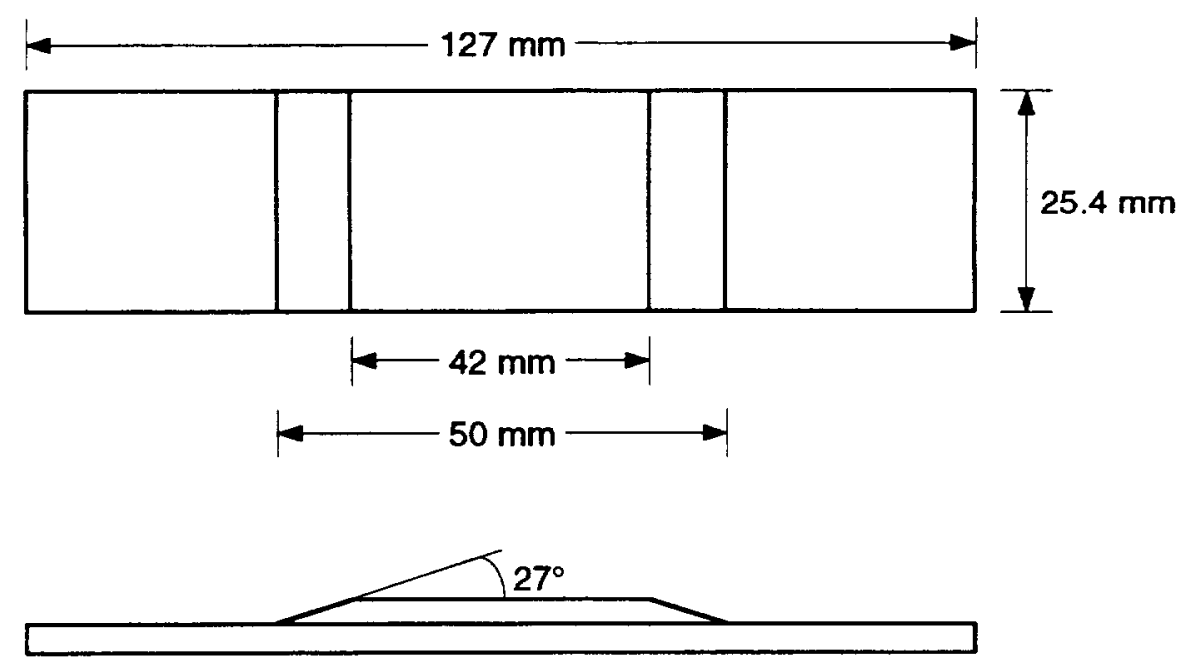

a) Specimen configuration



Fig. 2-Four-point bending specimen configuration and test set-up. 


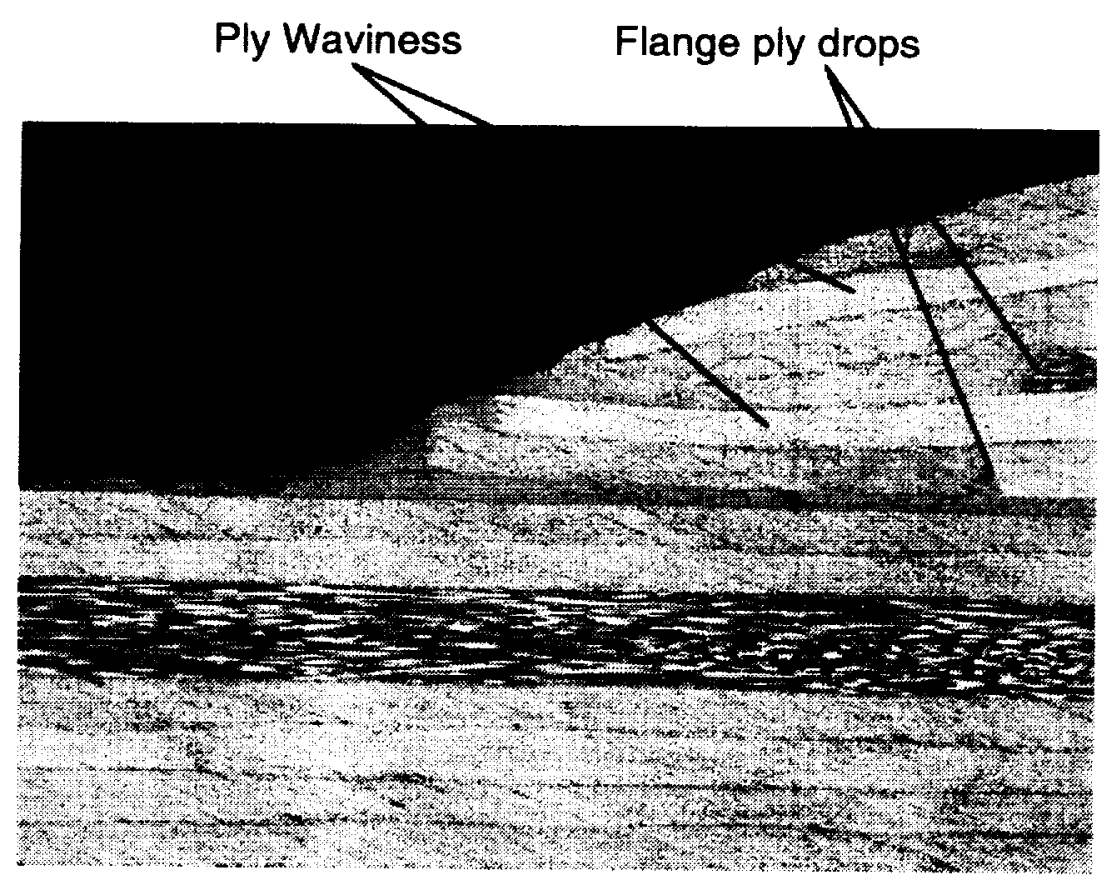

Fig. 3-Side view of a specimen of configuration D showing ply waviness and flange ply drops.



Fig. 4-Four-point bending specimen with crack locations and surface ply orientations. 




Fig. 5-Three-point bend rig with specimen in place.

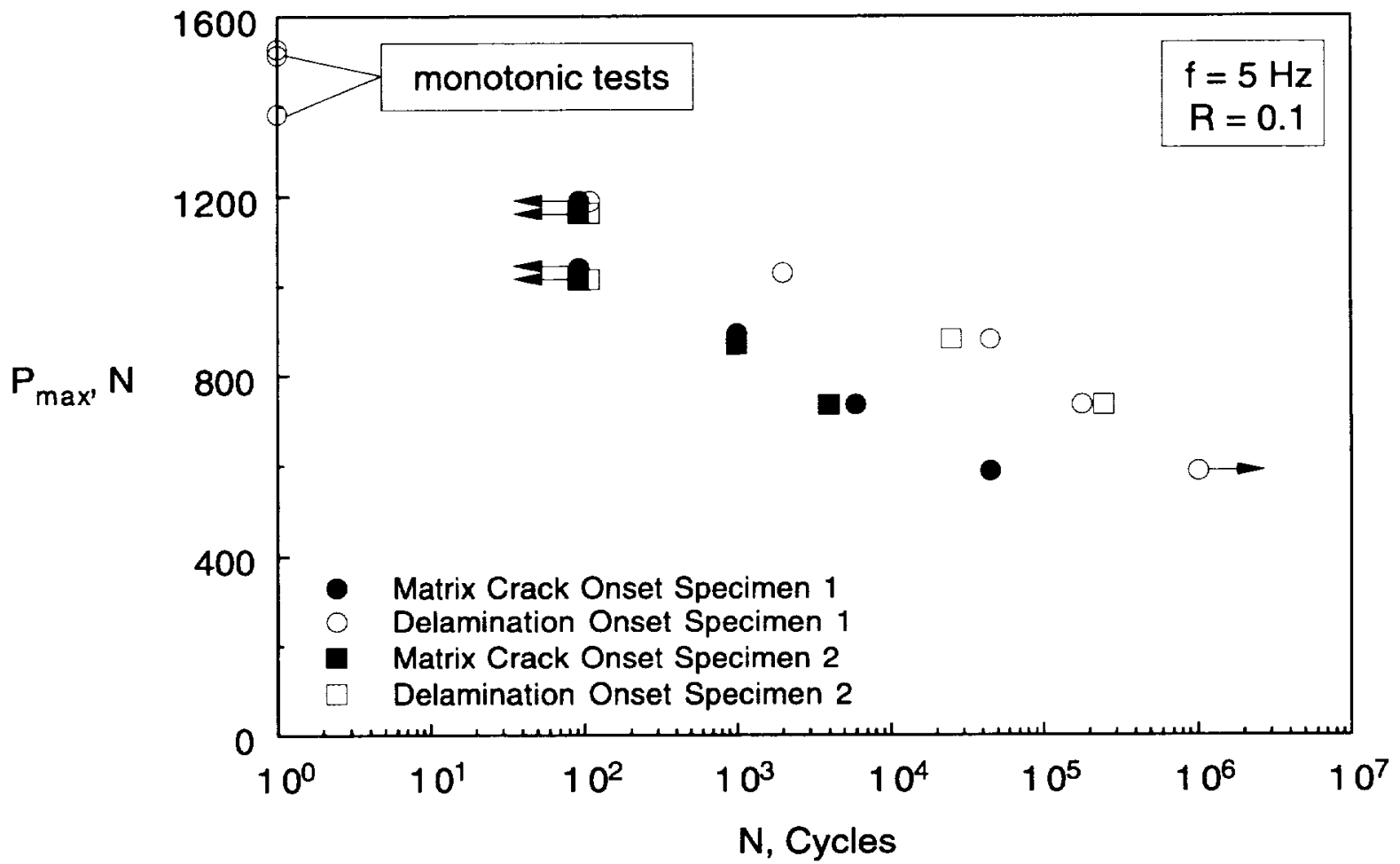

Fig. 6-Maximum cyclic load as a function of the number of cycles to matrix cracking and subsequent delamination onset for configuration $\mathrm{A}$. 




a) "B"-delaminations: positions 2 and 3

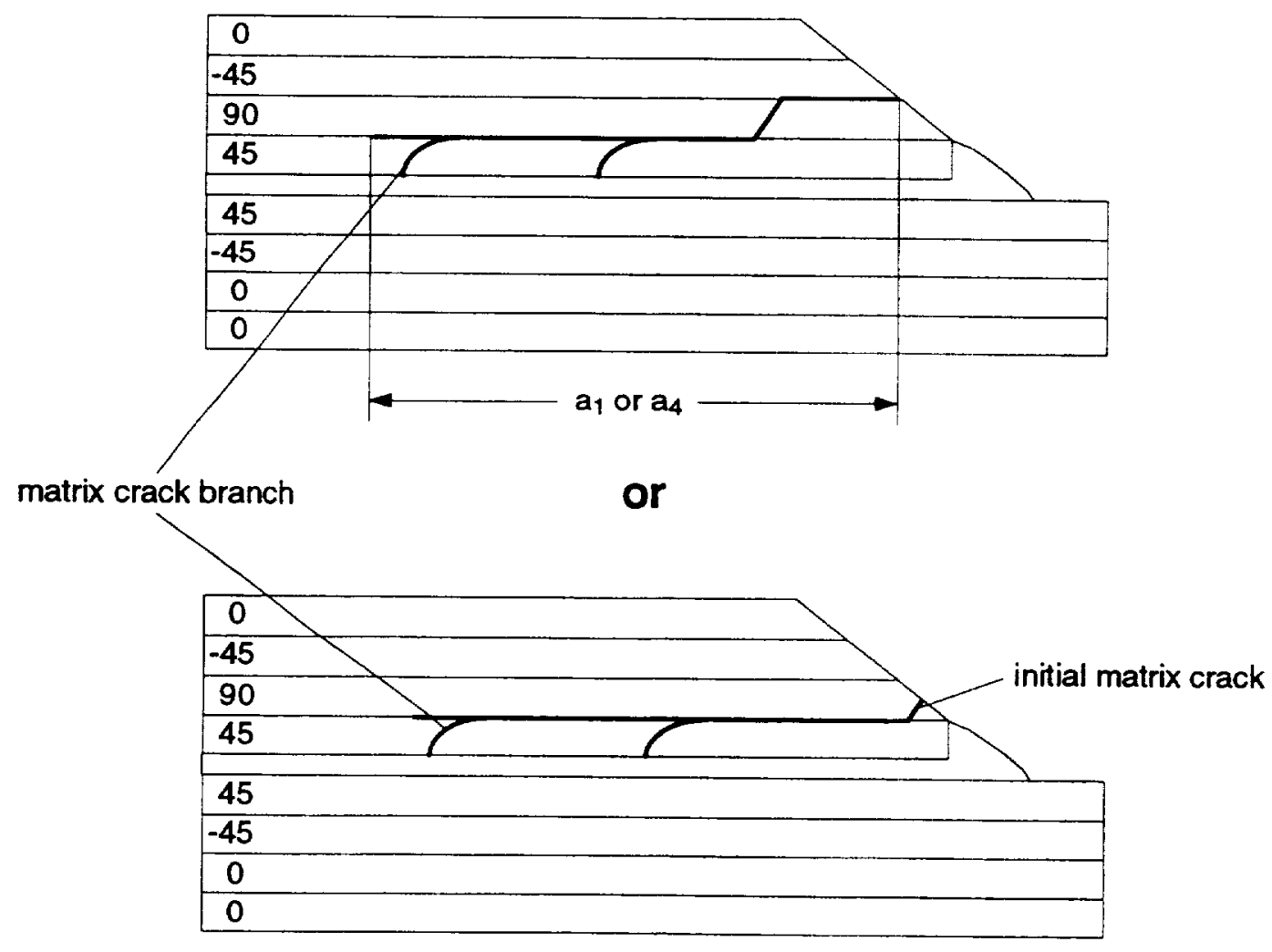

b) "P"-delaminations: positions 1 and 4

Fig. 7-Typical damage patterns in specimens of configuration A. 


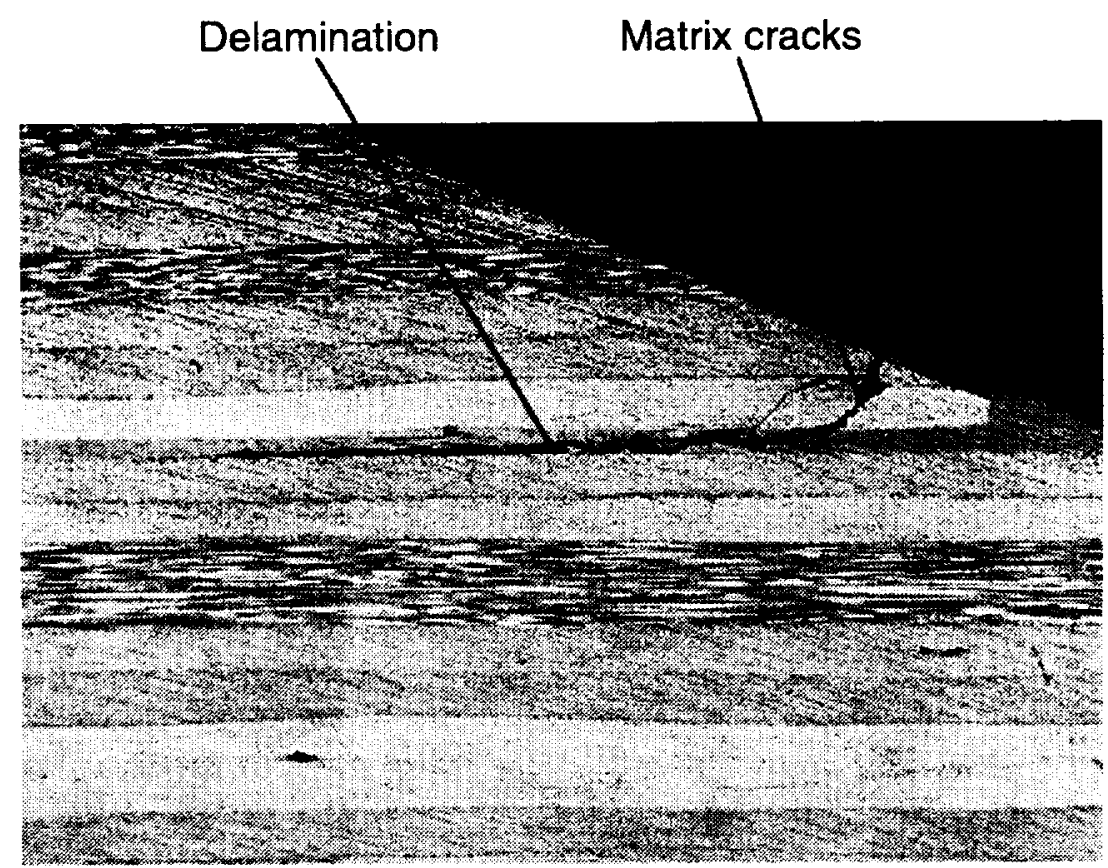

Fig. 8-Side view of a failed specimen of configuration A at a load level of $80 \%$ of $P_{n l}$ showing a type "B" delamination between skin and flange at the bondline at corner 2 .

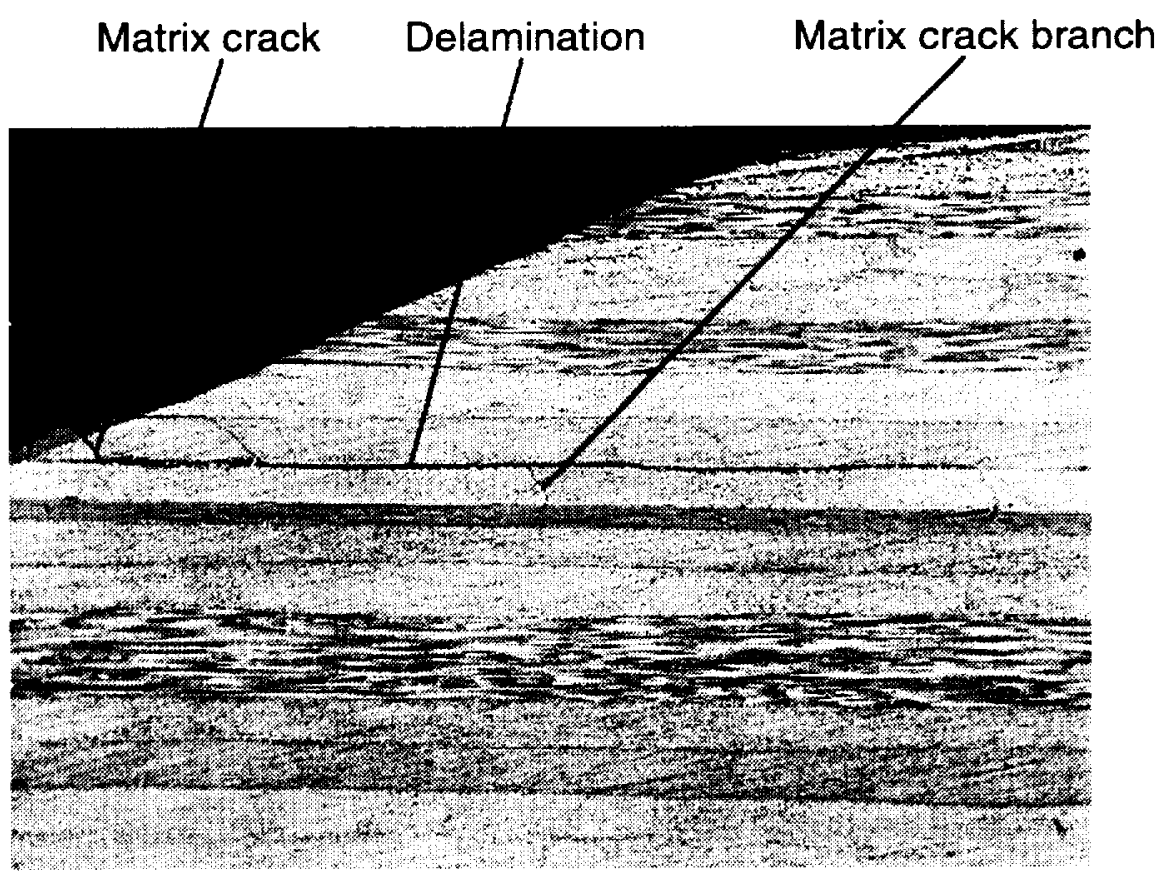

Fig. 9-Side view of a failed specimen of configuration A at a load level of $80 \%$ of $P_{n l}$ showing a type "P" delamination in the $90^{\circ} / 45^{\circ}$ flange interface at corner 4. 




Fig. 10-Delamination length versus number of cycles for specimen A2 at $80 \%$ of Pnl.

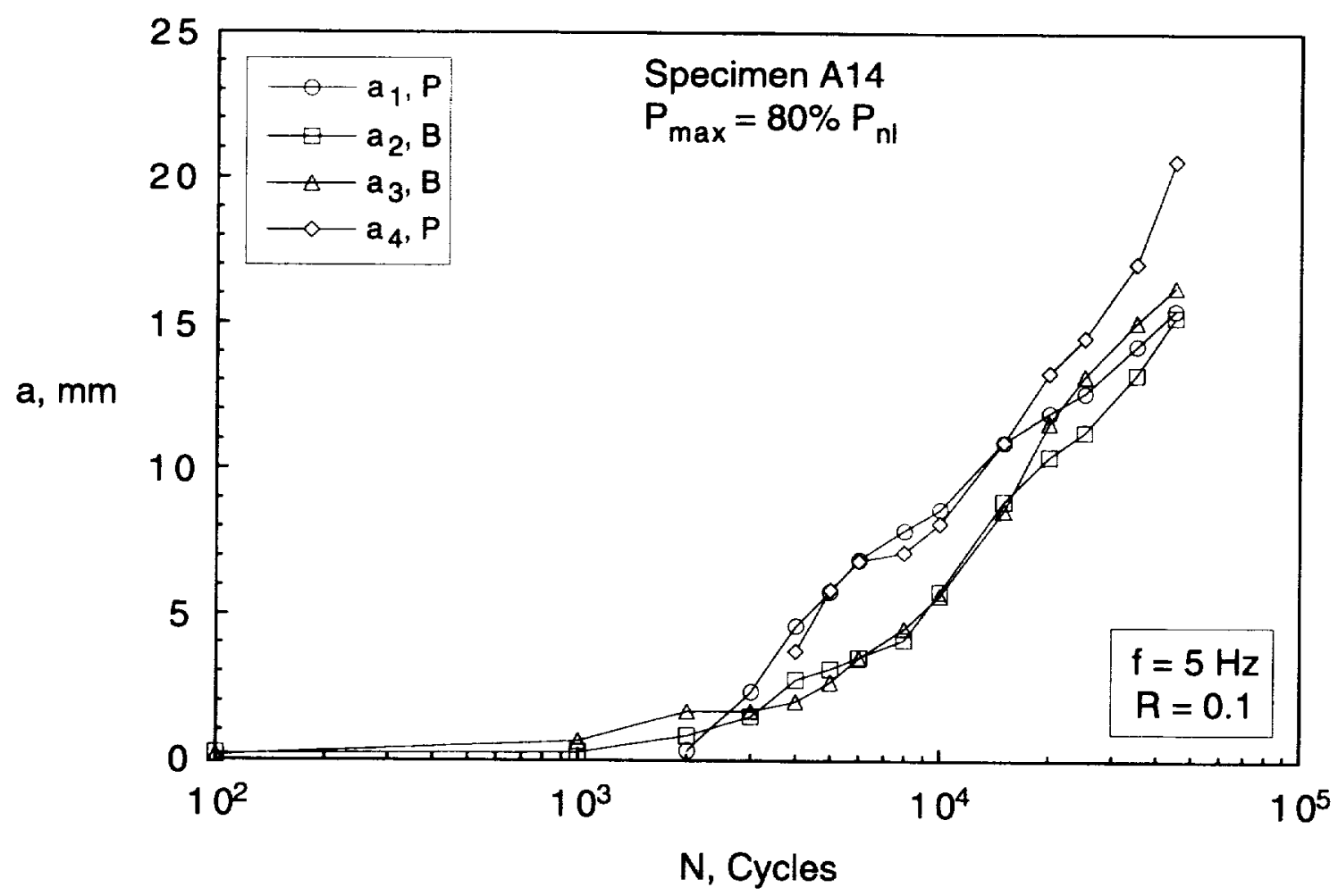

Fig. 11-Delamination length versus number of cycles for specimen A14 at $80 \%$ of $P n l$. 


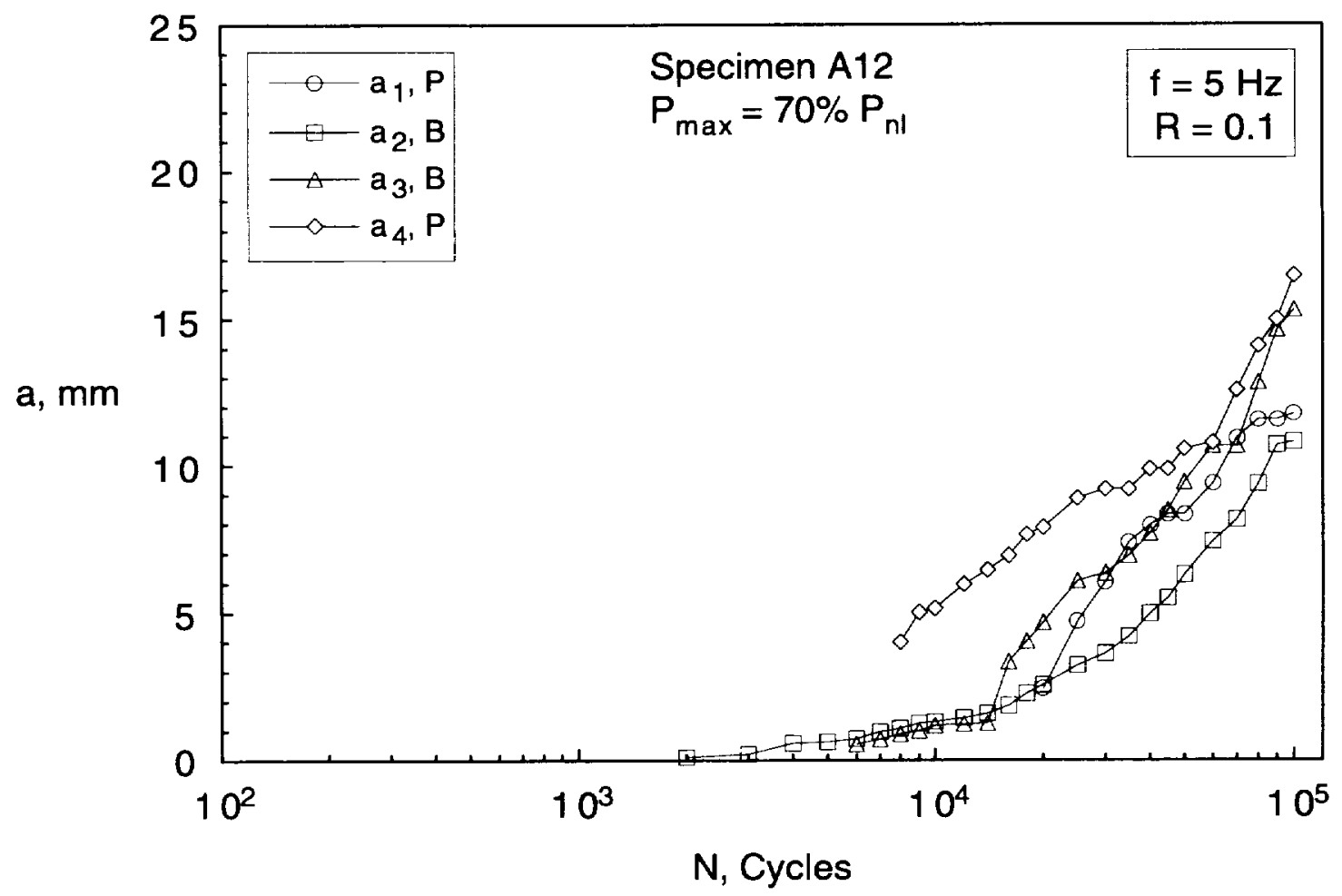

Fig. 12-Delamination length versus number of cycles for specimen A12 at 70\% of Pnl.

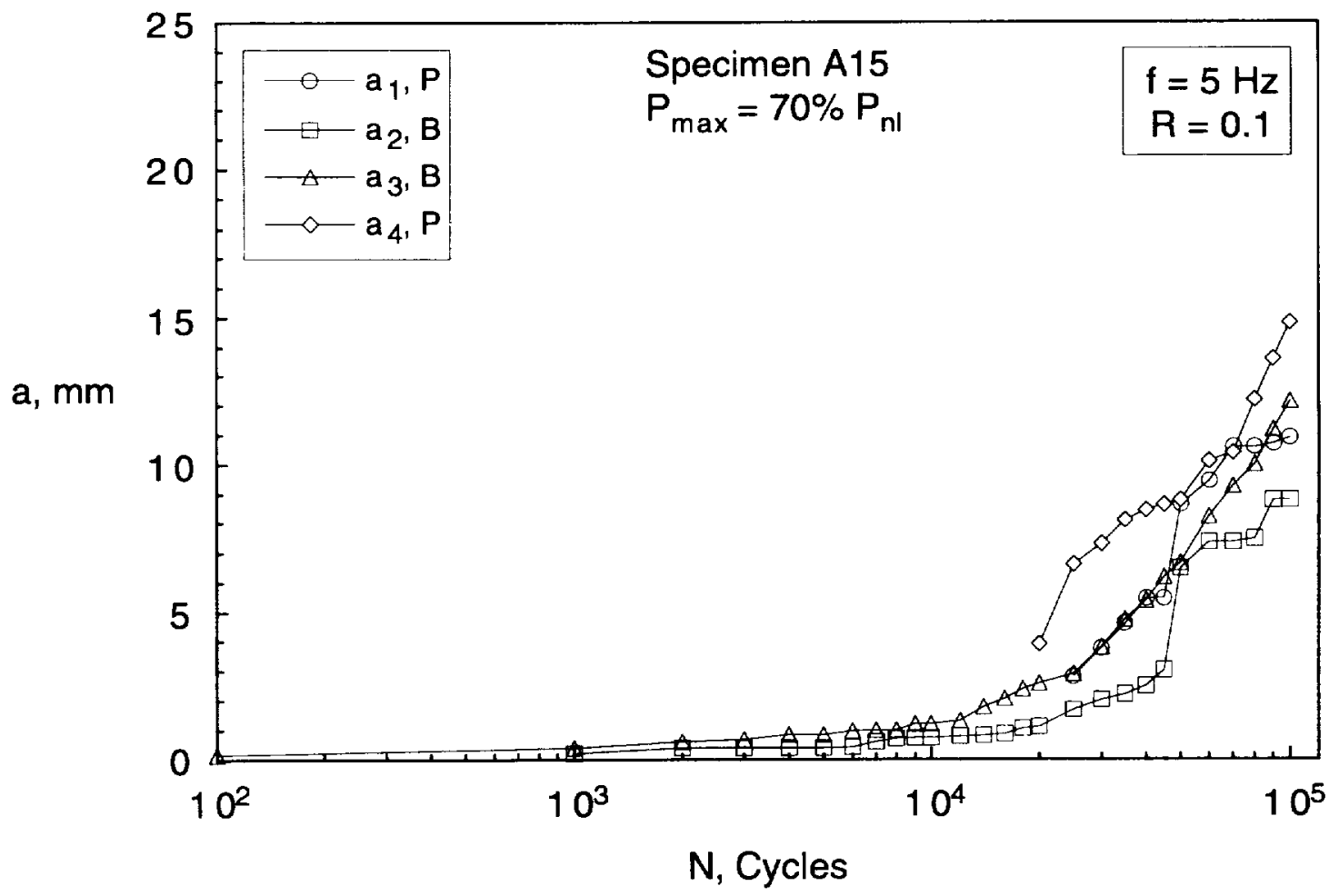

Fig. 13-Delamination length versus number of cycles for specimen A15 at 70\% of Pnl. 


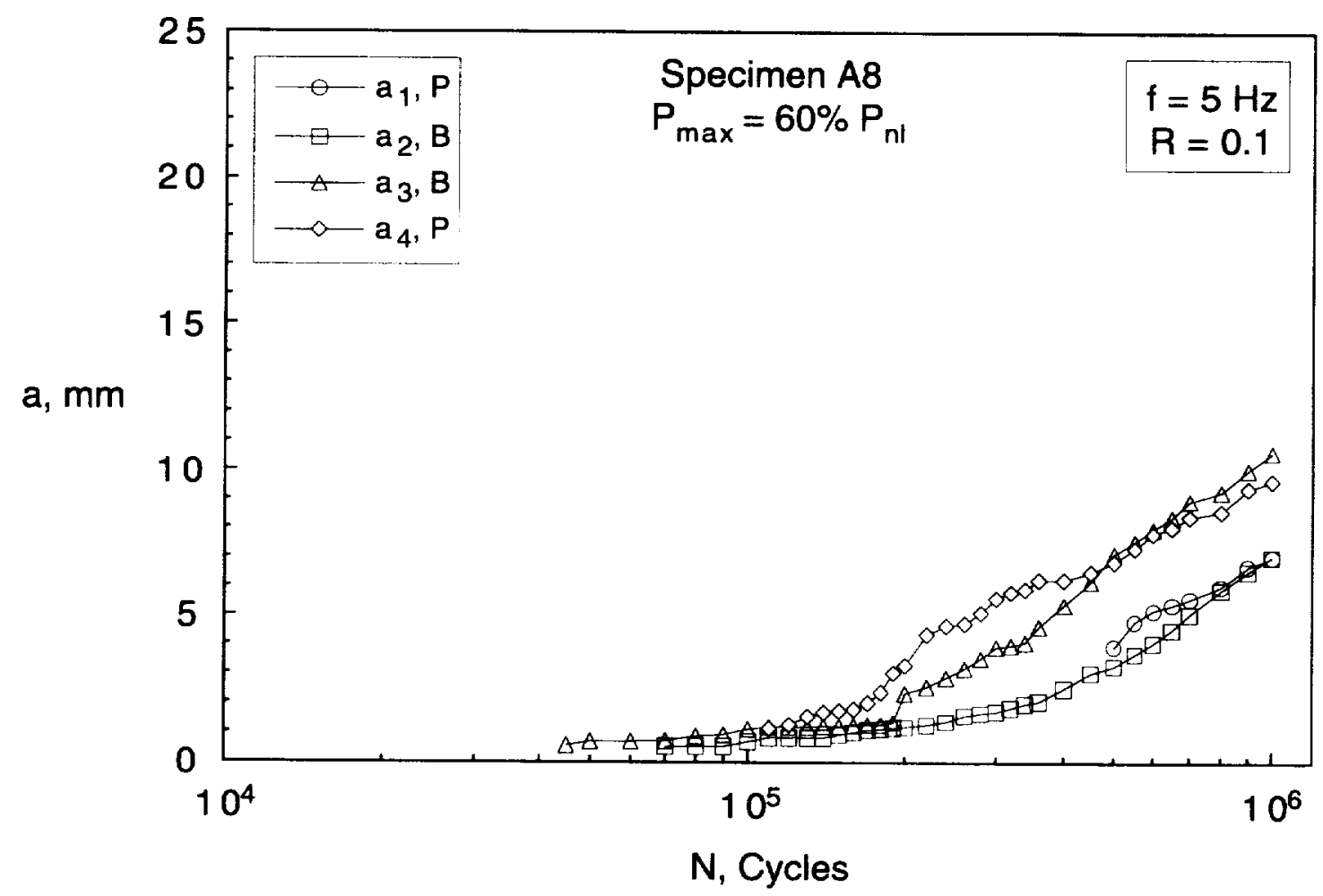

Fig. 14 Delamination length versus number of cycles for specimen A8 at $60 \%$ of Pnl.

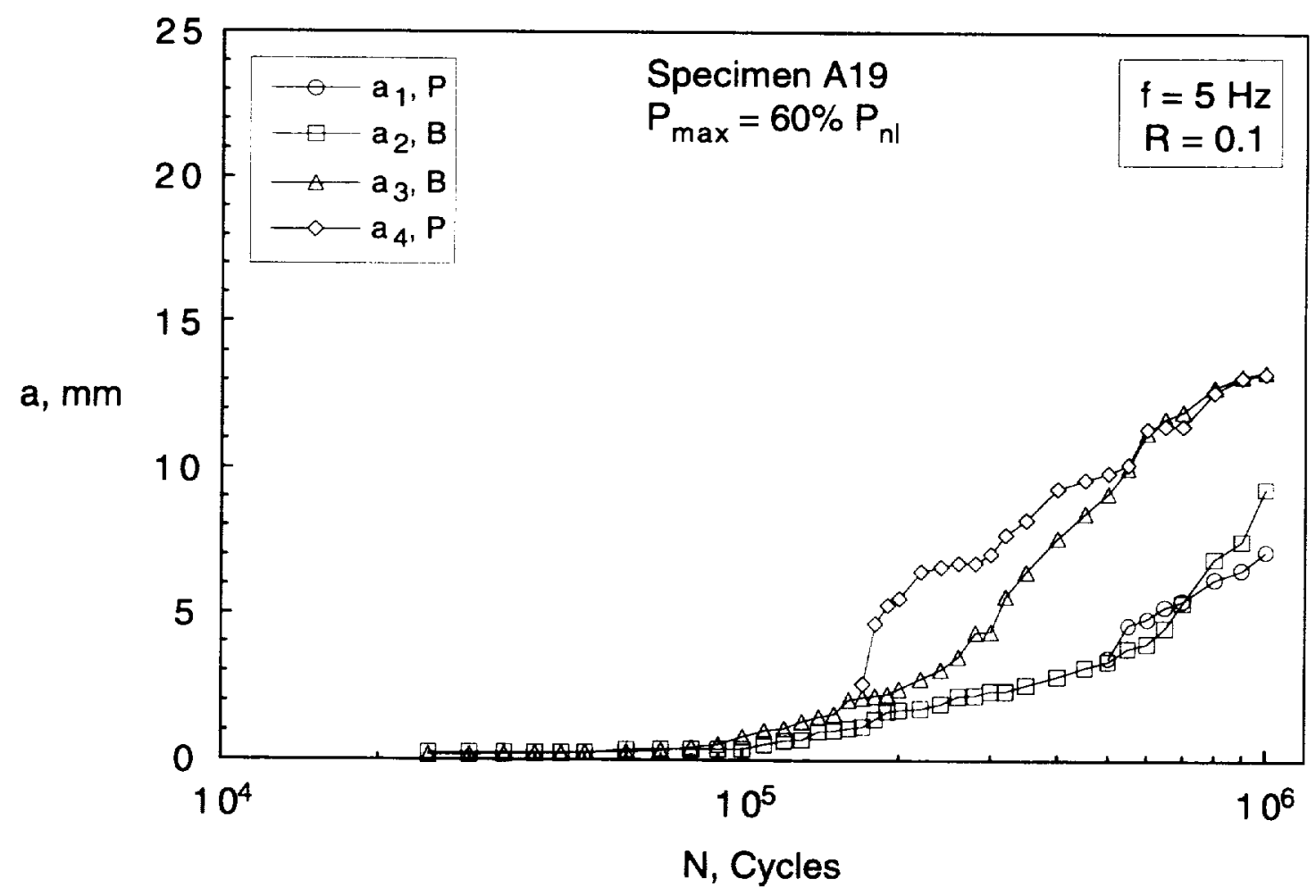

Fig. 15-Delamination length versus number of cycles for specimen A19 at $60 \%$ of Pnl. 


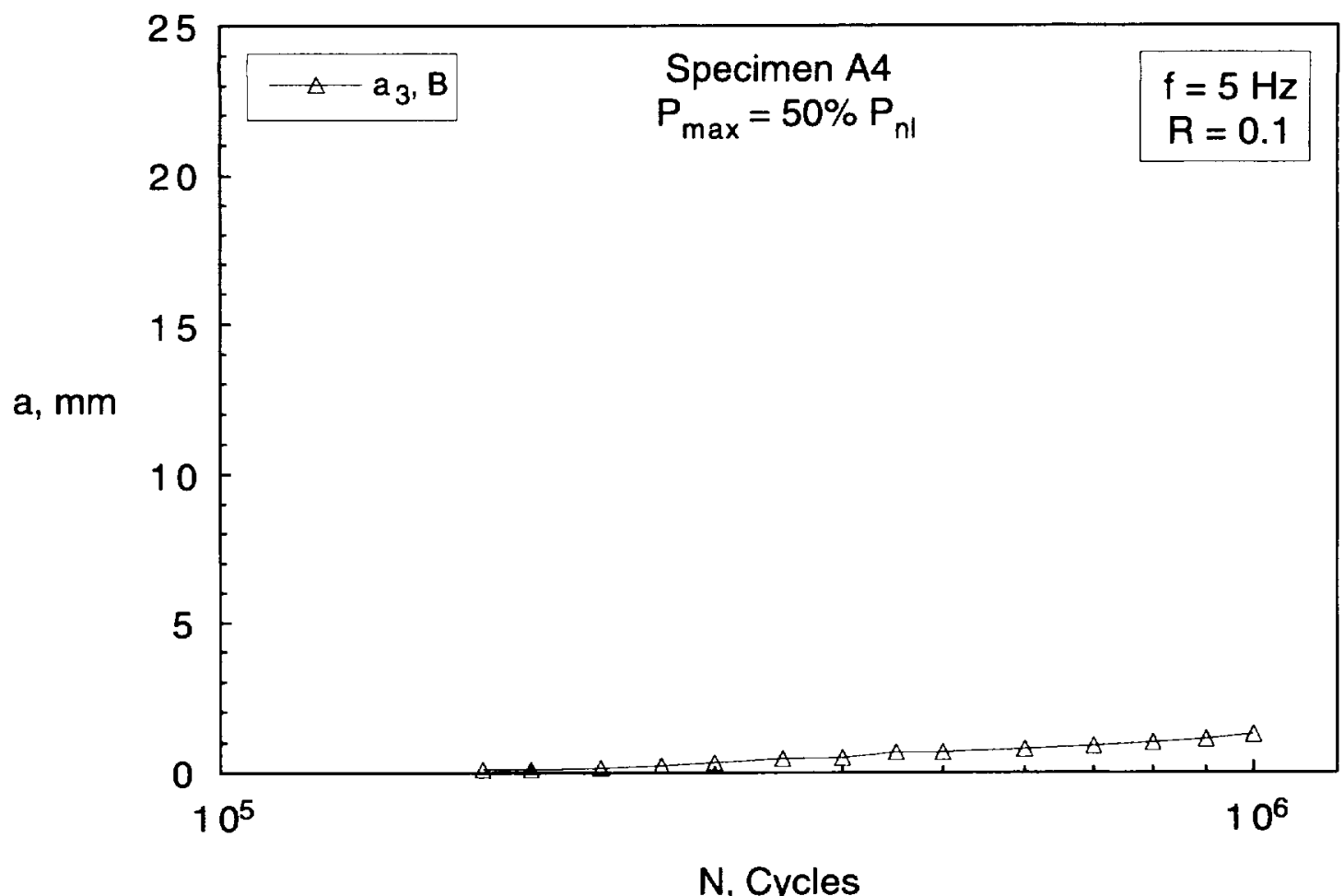

Fig. 16-Delamination length versus number of cycles for specimen A4 at $50 \%$ of Pnl.



Fig. 17-Delamination length versus number of cycles for specimen A20 at $50 \%$ of Pnl. 


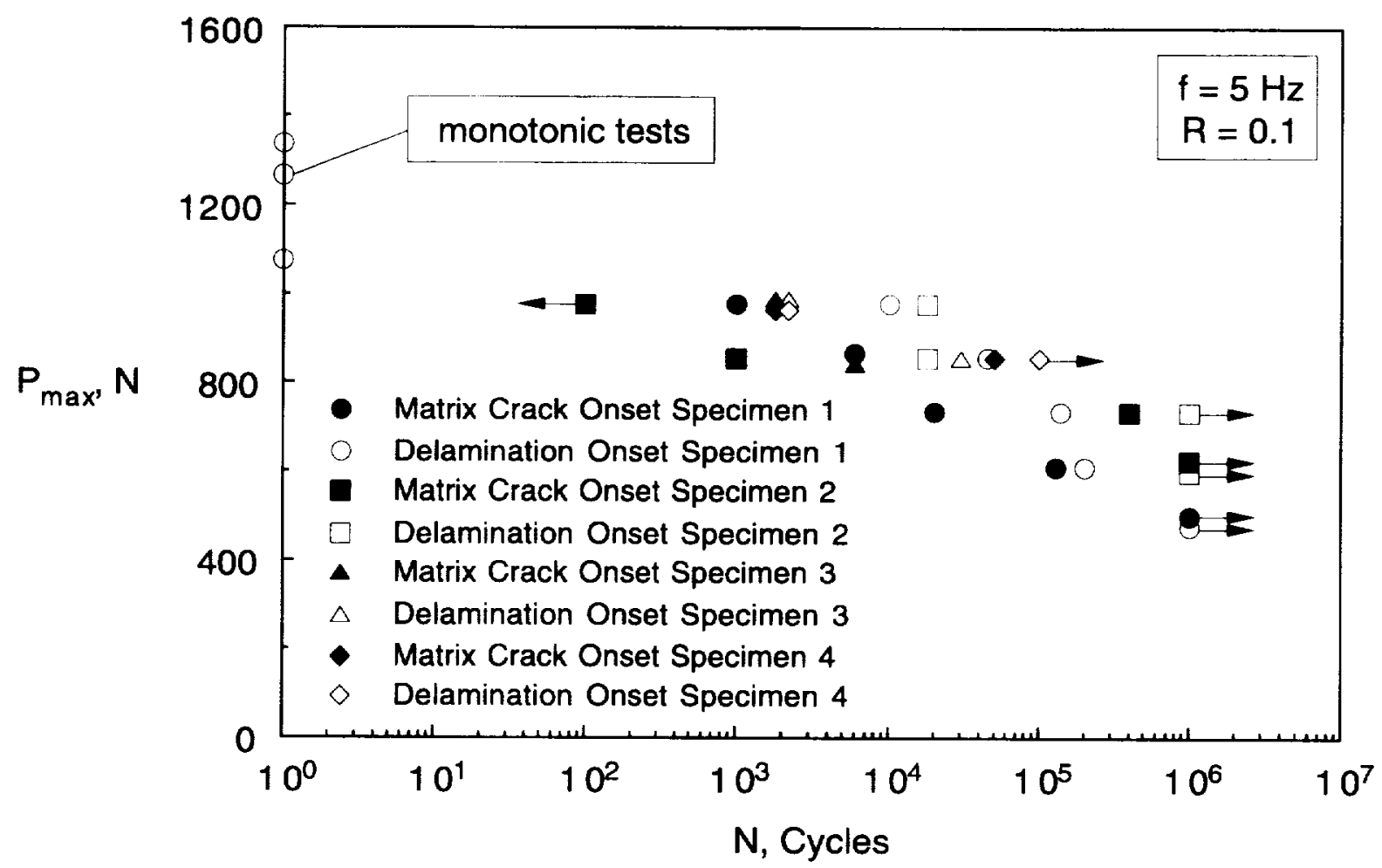

Fig. 18-Maximum cyclic load as a function of the number of cycles to matrix cracking and subsequent delamination onset for configuration $\mathrm{D}$.



Fig. 19-Maximum cyclic load as a function of the number of cycles to matrix cracking onset for configuration D. 


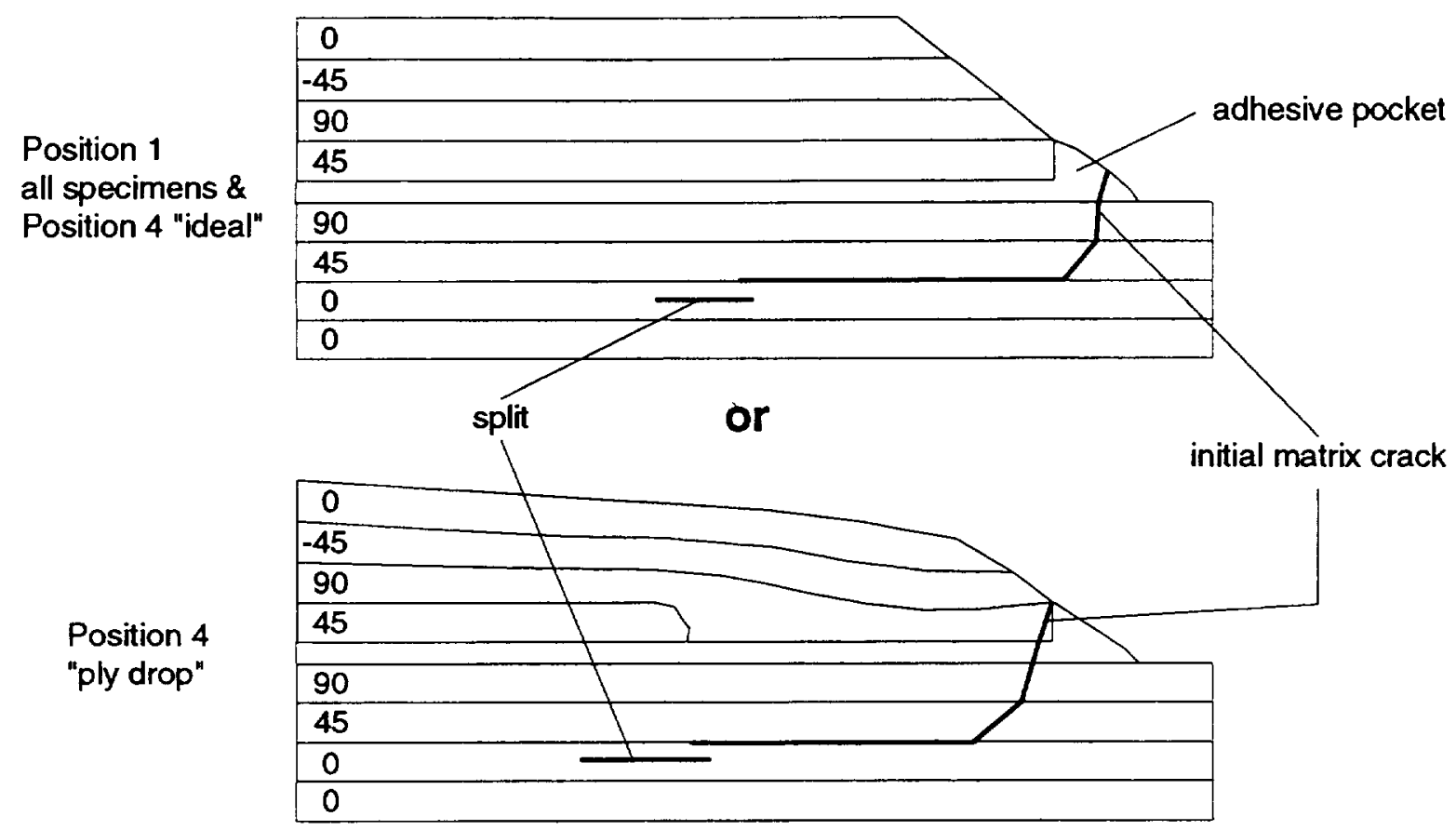

a) Positions 1 and 4

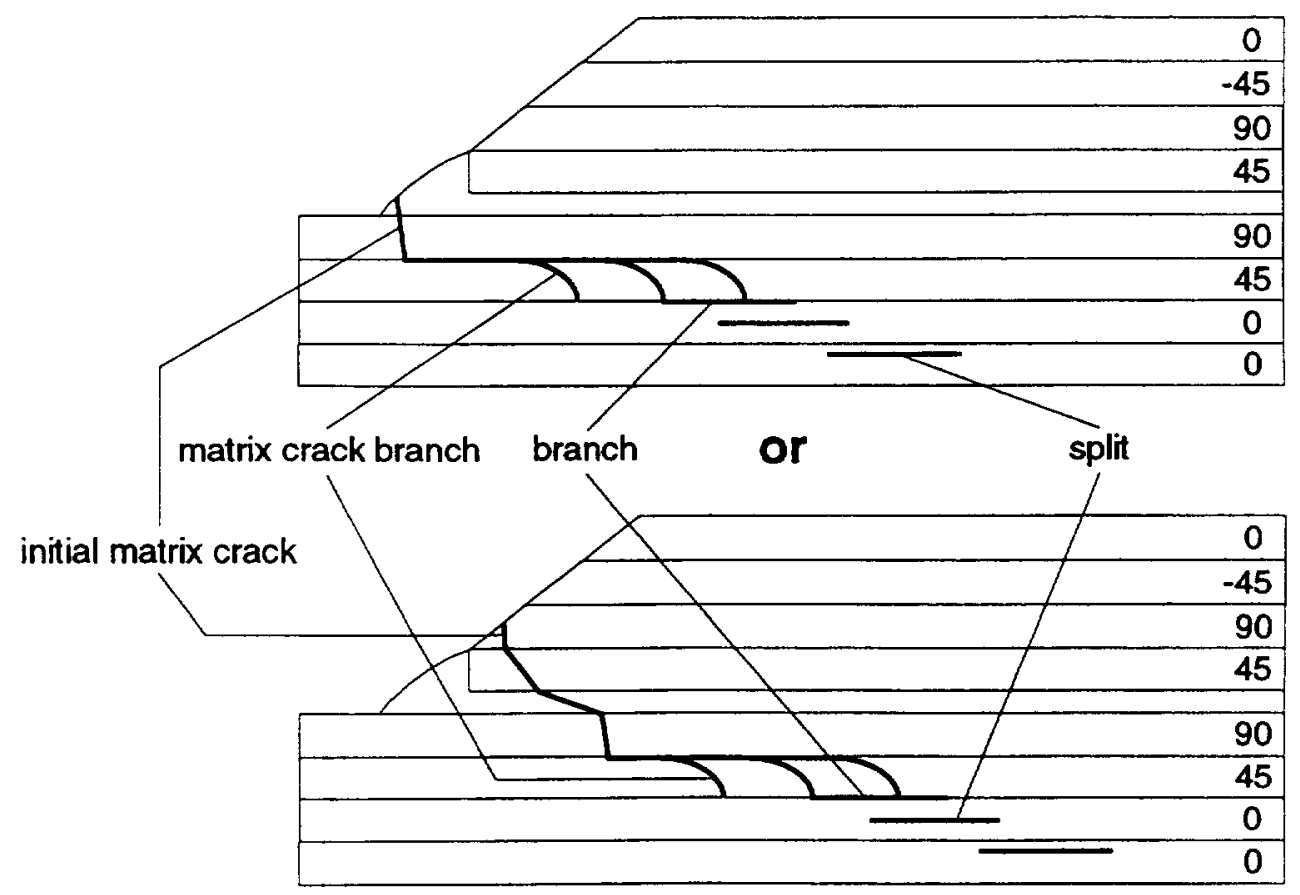

b) Positions 2 and 3

Fig. 20-Typical damage patterns in specimens of configuration $D$. 







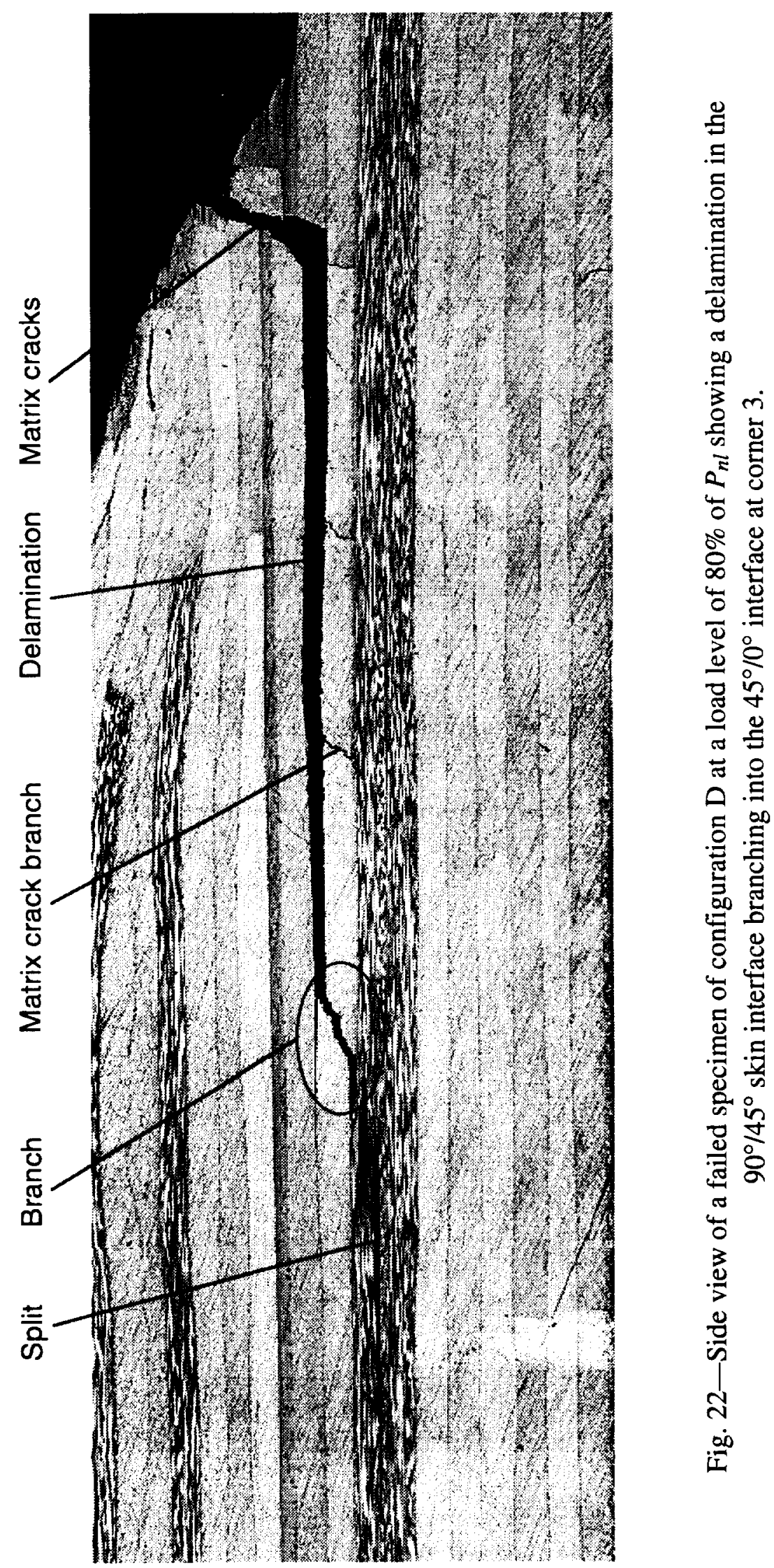




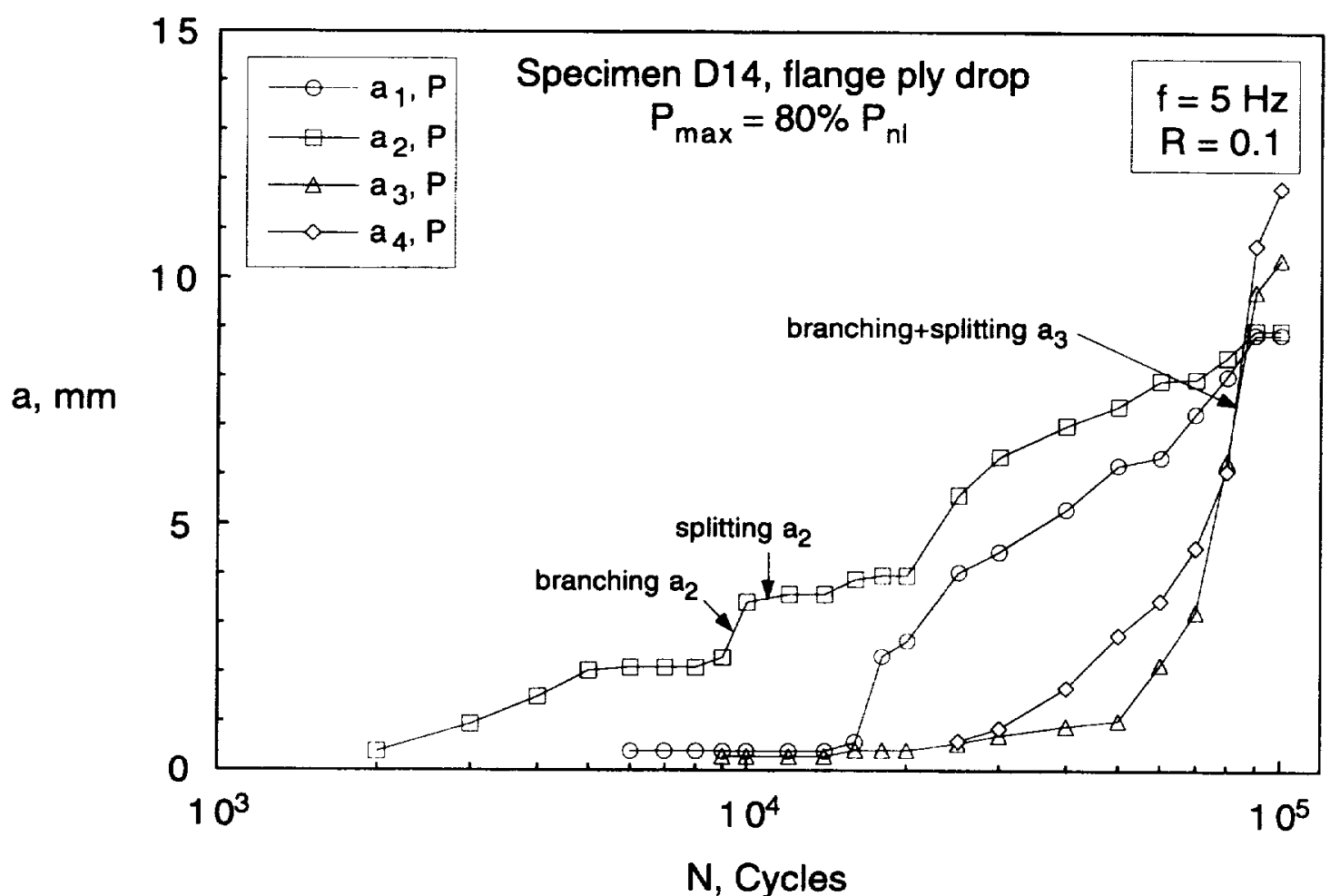

Fig. 23-Delamination length versus number of cycles for specimen D14 at $80 \%$ of Pnl.

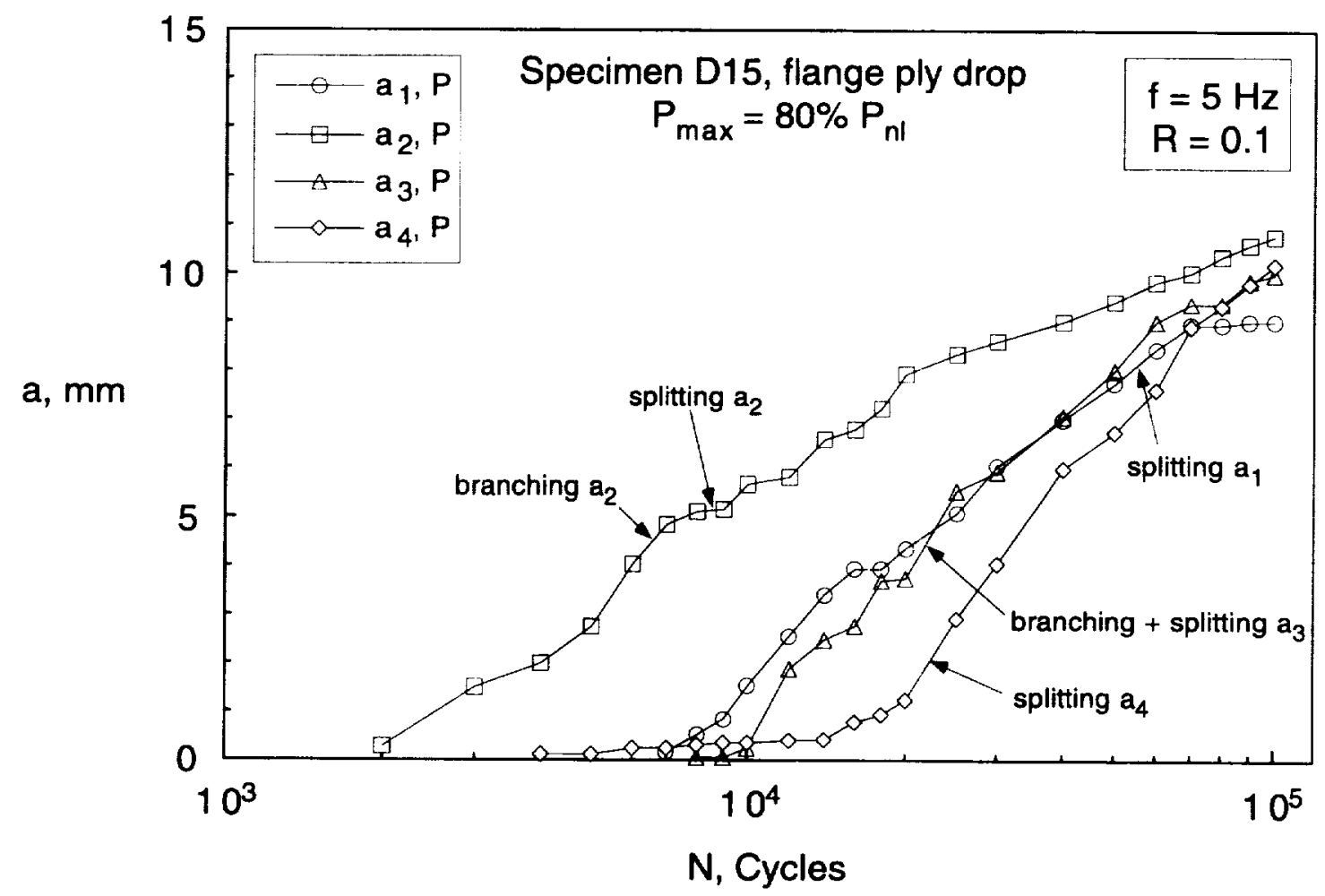

Fig. 24-Delamination length versus number of cycles for specimen D15 at $80 \%$ of Pnl. 


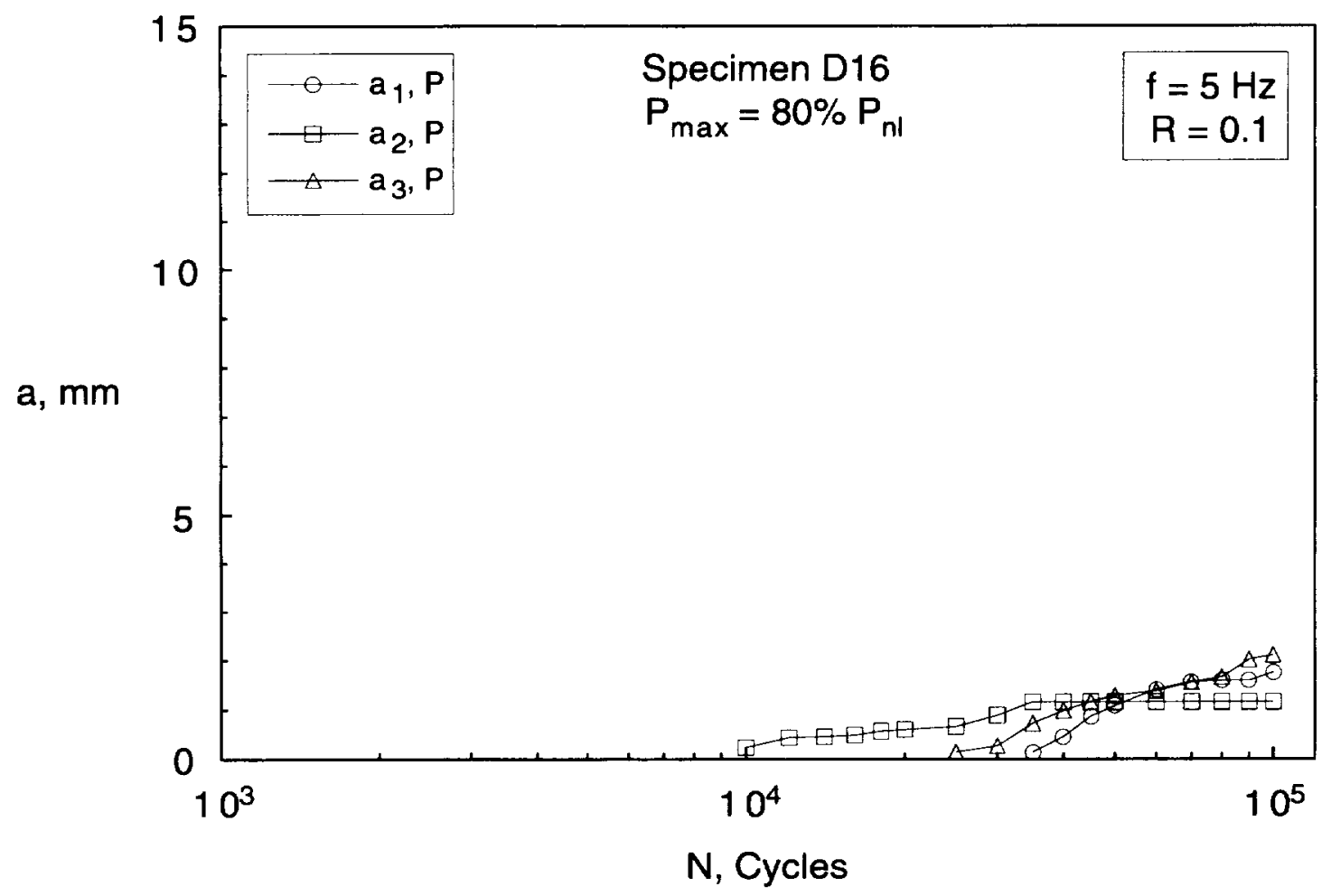

Fig. 25-Delamination length versus number of cycles for specimen D16 at $80 \%$ of Pnl.

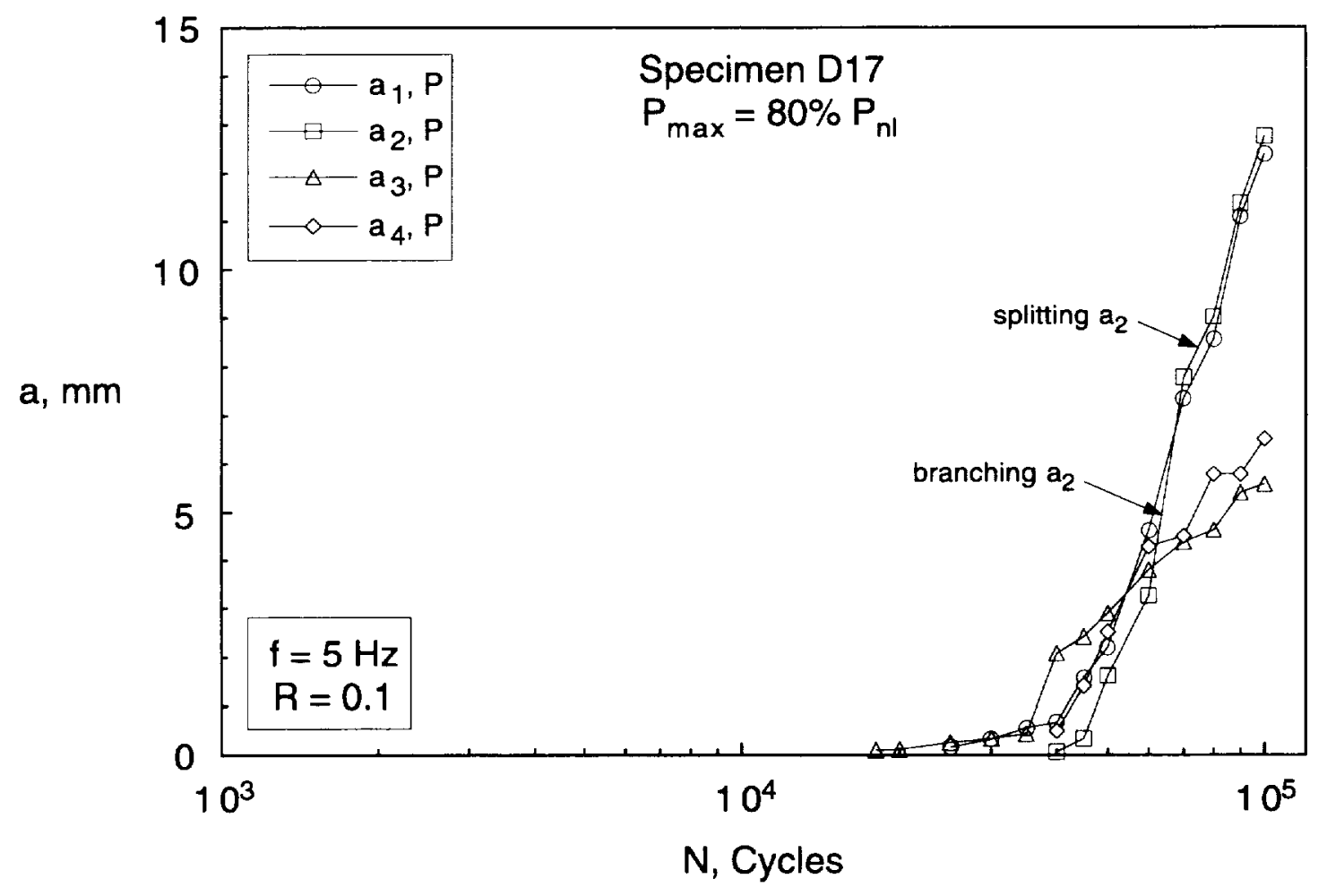

Fig. 26-Delamination length versus number of cycles for specimen D17 at $80 \%$ of Pnl. 


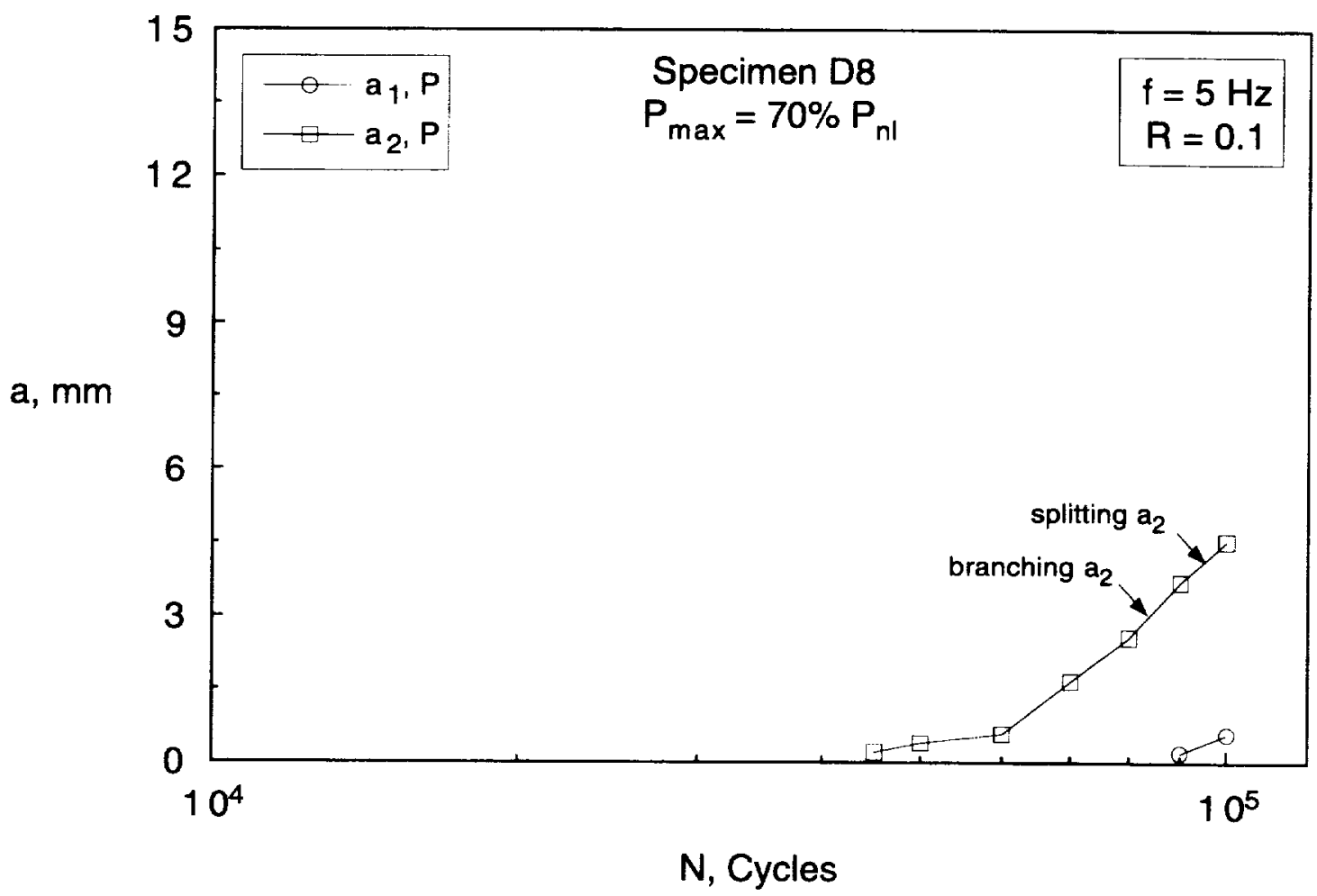

Fig. 27-Delamination length versus number of cycles for specimen D8 at $70 \%$ of Pnl.



Fig. 28-Delamination length versus number of cycles for specimen D11 at $70 \%$ of Pnl. 


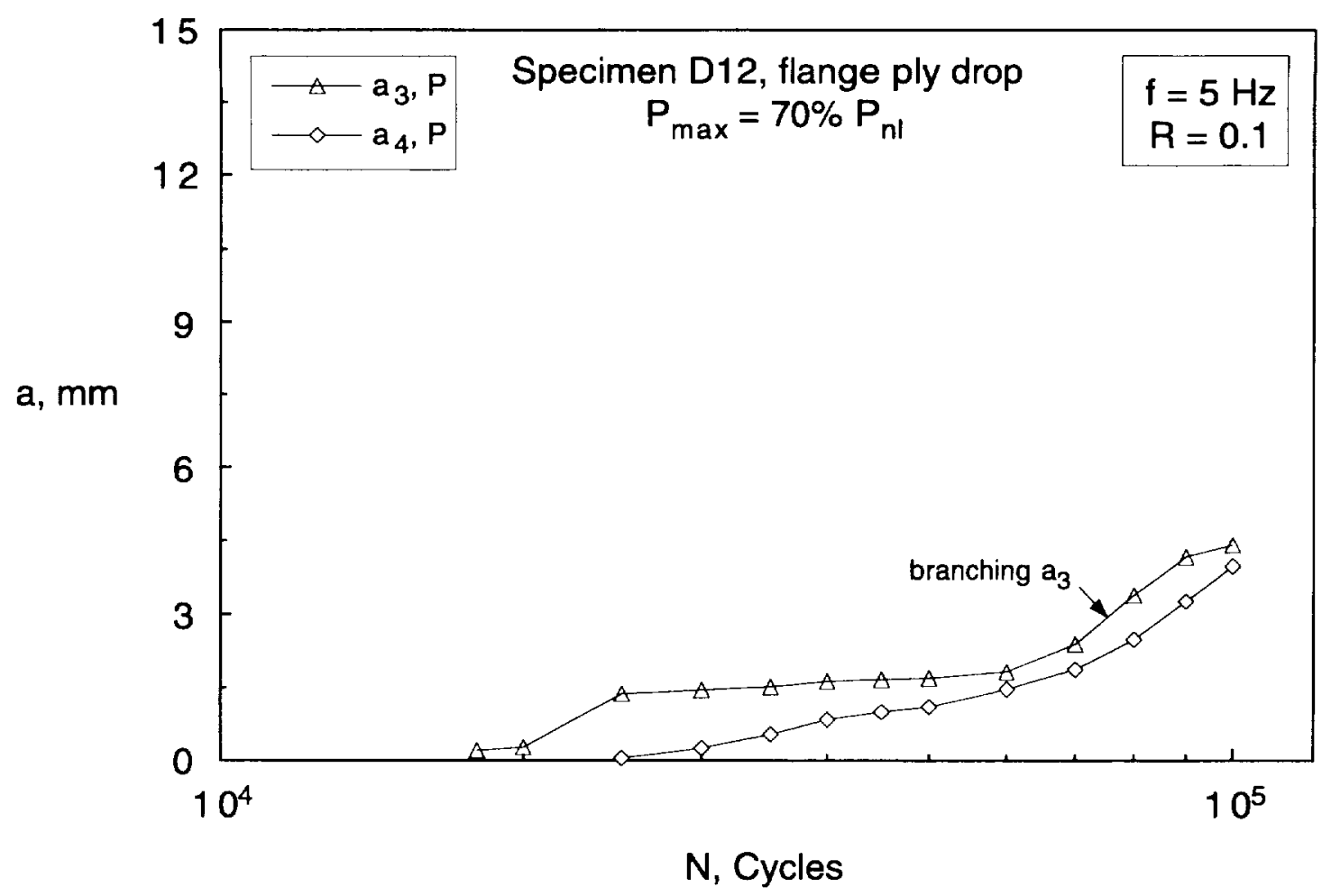

Fig. 29-Delamination length versus number of cycles for specimen D12 at $70 \%$ of Pnl.



Fig. 30-Delamination length versus number of cycles for specimen D6 at $60 \%$ of Pnl. 


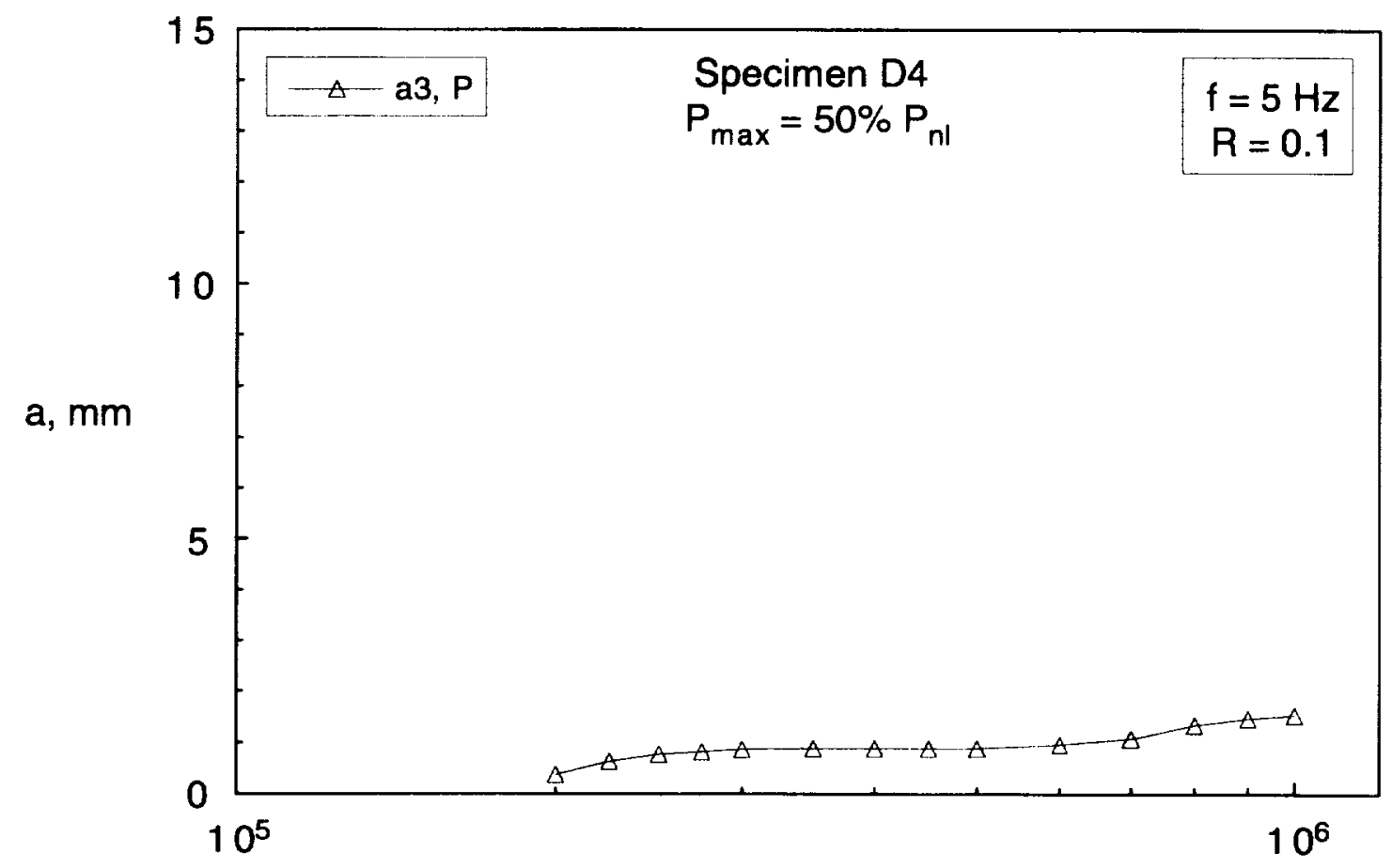

\section{N, Cycles}

Fig. 31-Delamination length versus number of cycles for specimen D4 at 50\% of Pnl.

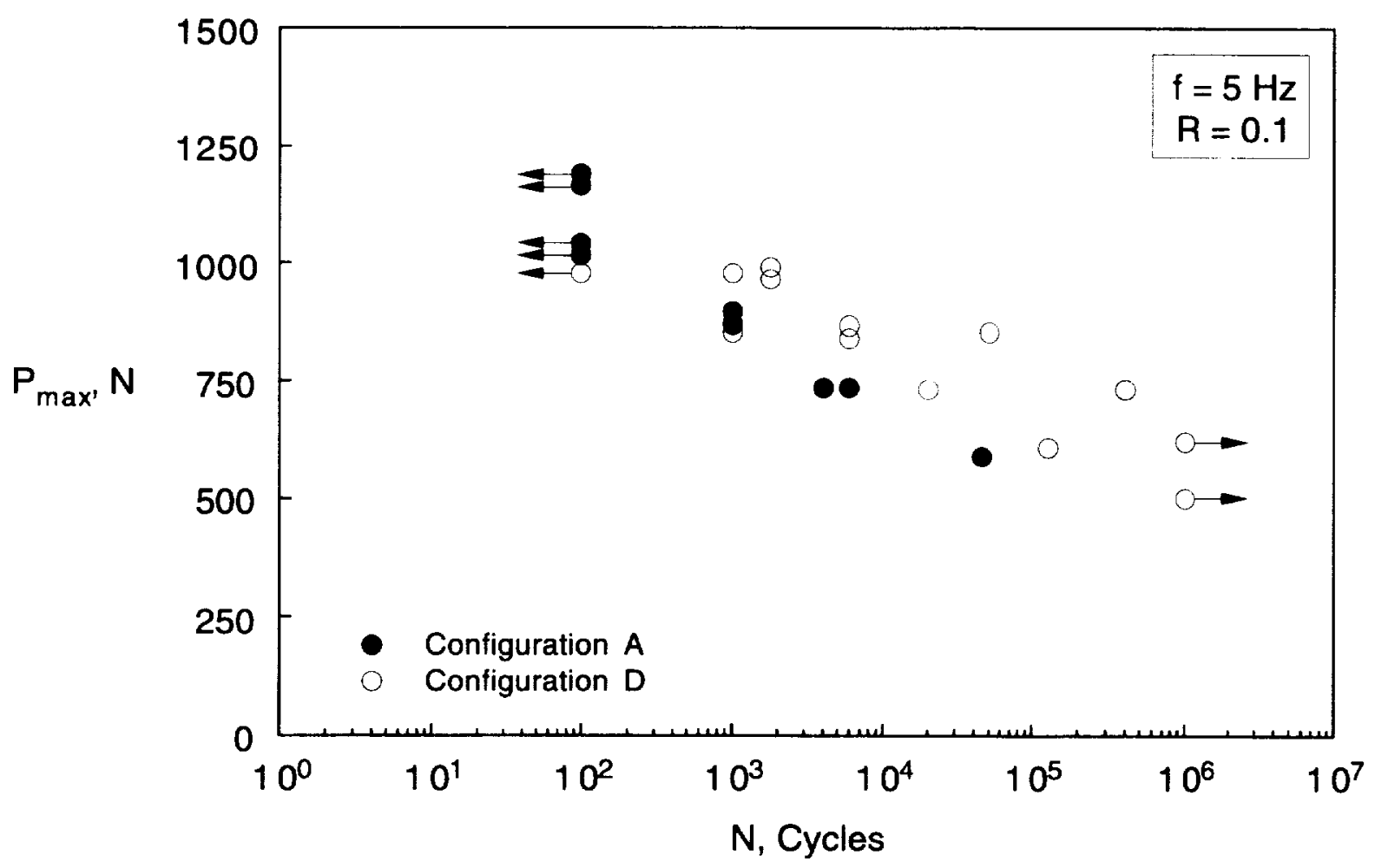

Fig. 32-Comparison of the maximum cyclic load as a function of the number of cycles to matrix crack onset. 


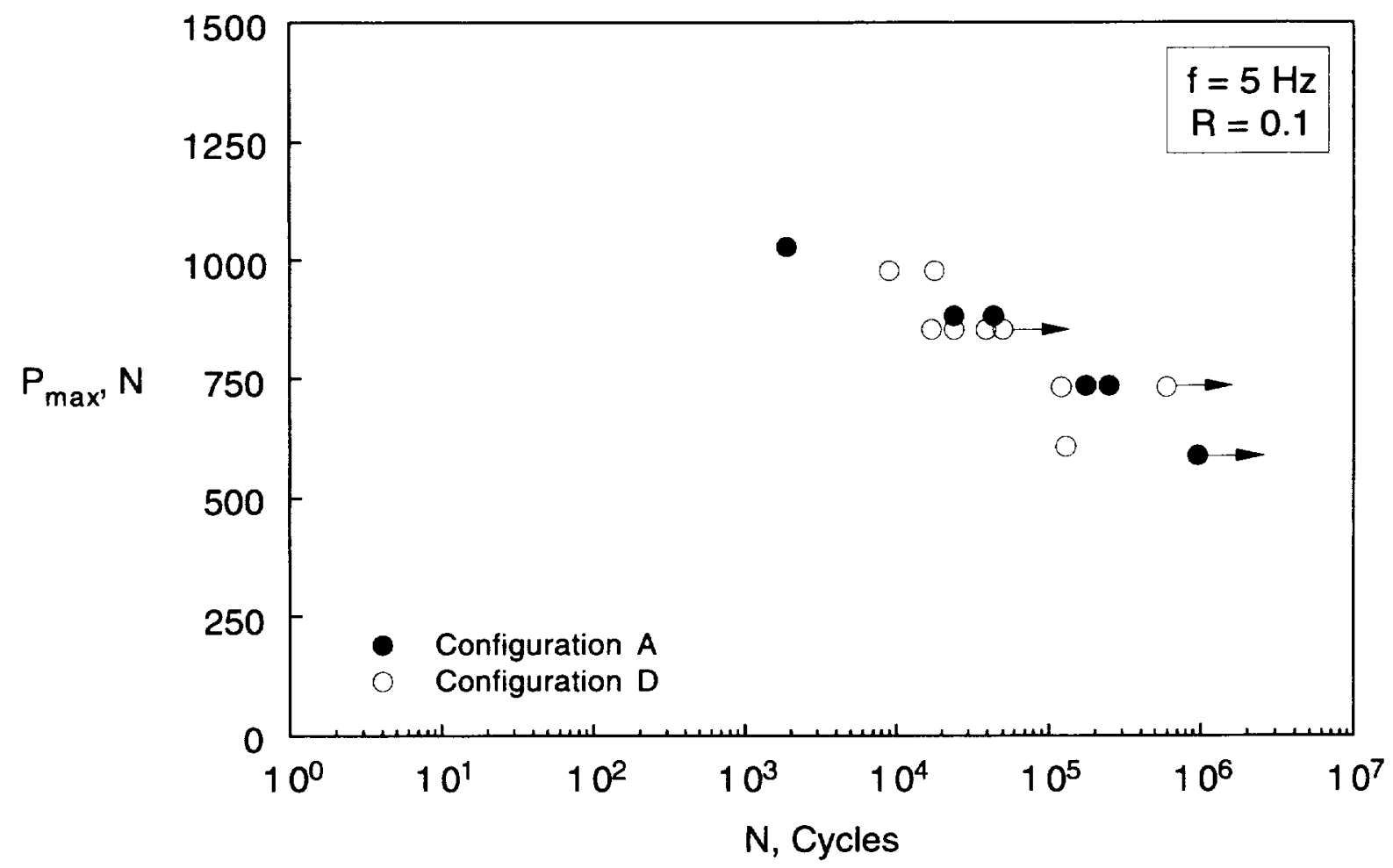

Fig. 33-Comparison of the maximum cyclic load as a function of the number of cycles to delamination onset once a matrix crack is present. 


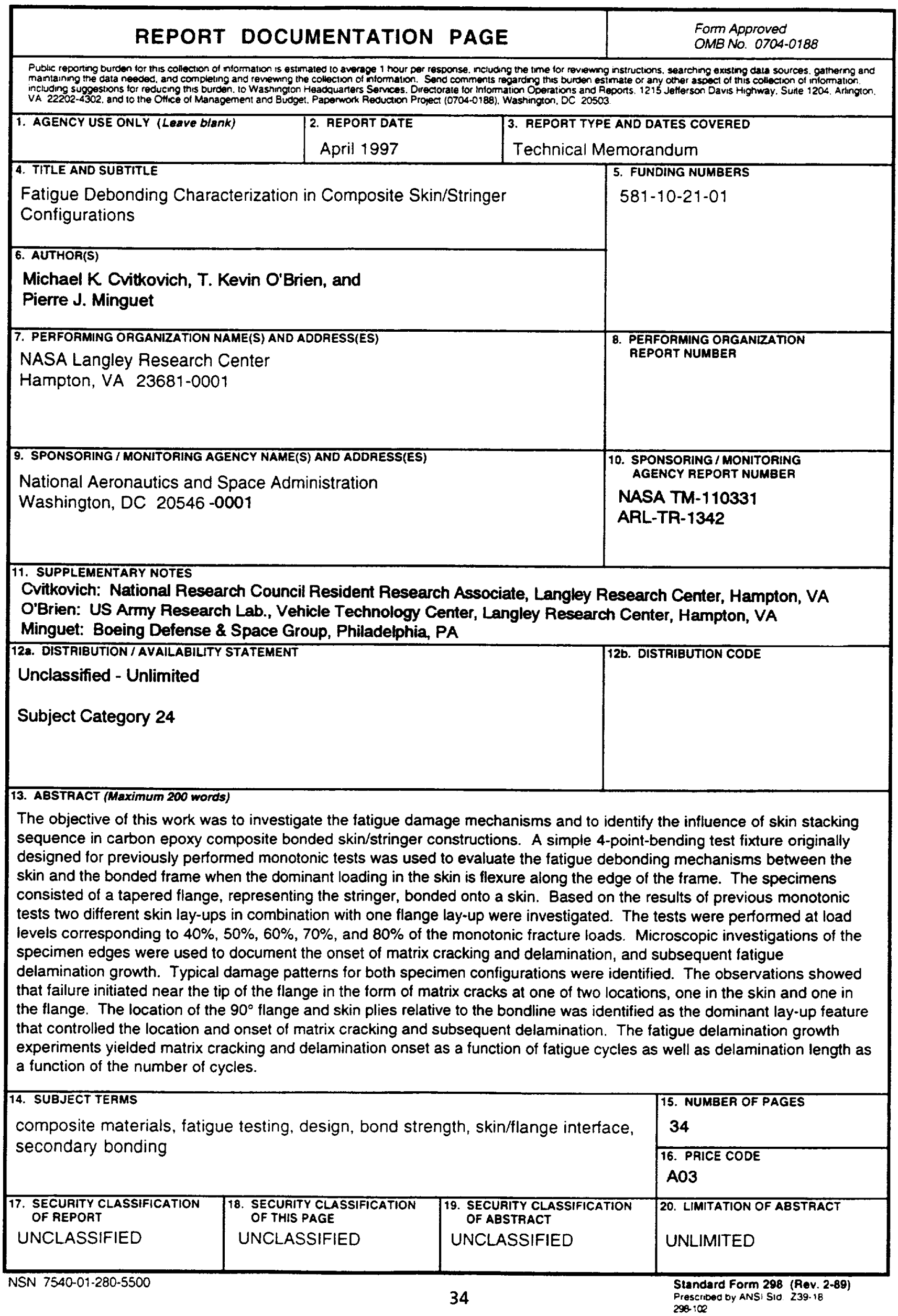

